\title{
Recycled Glass Fiber Reinforced Polymer Composites Incorporated in Mortar for Improved Mechanical Performance
}
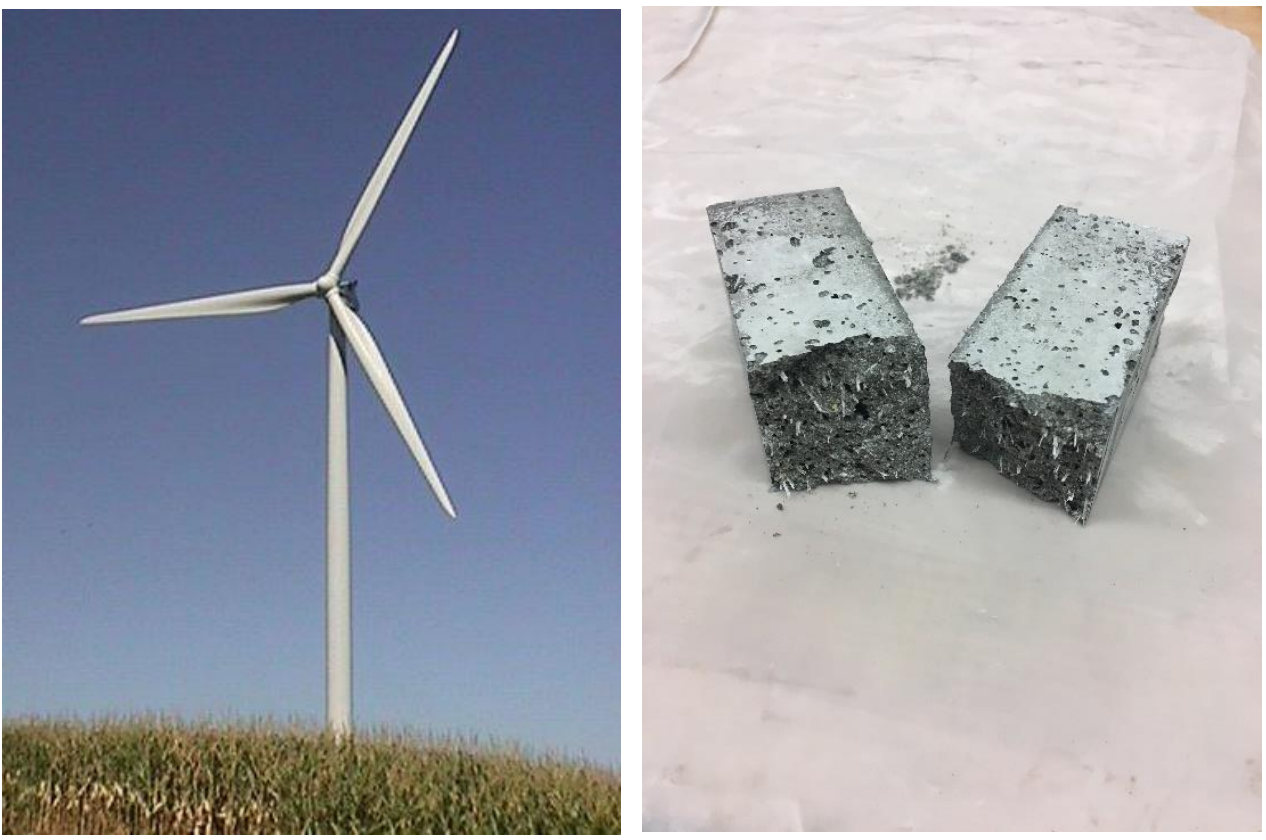

Authors:

Harry Rodin III, Somayeh Nassiri, Karl Englund,

Osama Fakron, Hui Li

Department of Civil and Environmental Engineering

Washington State University

Date: December 11, 2017

Prepared by:

Center for Environmentally Sustainable U.S. Department of Transportation

Transportation in Cold Climates

1200 New Jersey Avenue, SE

University of Alaska Fairbanks

P.O. Box 755900

Washington, DC 20590

Fairbanks, AK 99775

INE/AUTC 18.02
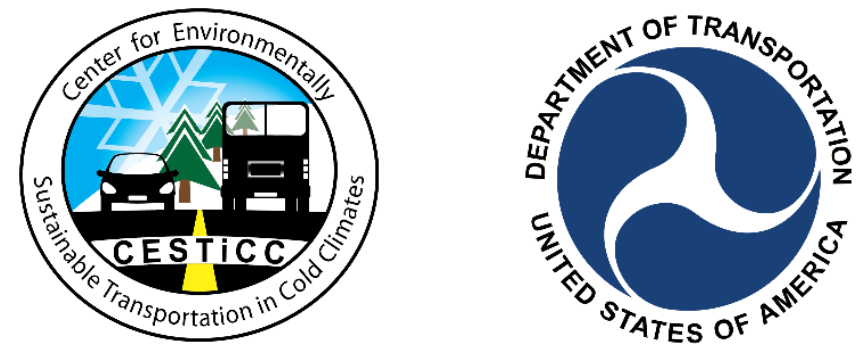


\section{REPORT DOCUMENTATION PAGE}

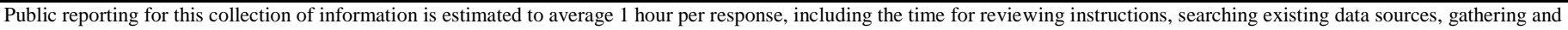

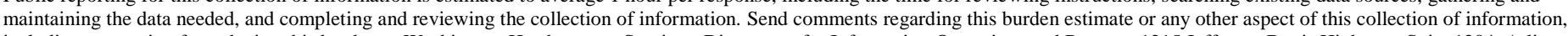

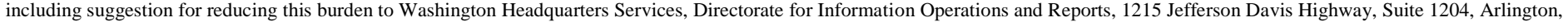
VA 22202-4302, and to the Office of Management and Budget, Paperwork Reduction Project (0704-1833), Washington, DC 20503

\begin{tabular}{l|l|l} 
1. AGENCY USE ONLY (LEAVE BLANK) & $\begin{array}{l}\text { 2. REPORT DATE } \\
\text { December 11, 2017 }\end{array}$ & $\begin{array}{l}\text { 3. REPORT TYPE AND DATES COVERED } \\
\text { Final Report: September 2016 to December 2017 }\end{array}$
\end{tabular}

\begin{tabular}{|l|l|}
\hline 4. TITLE AND SUBTITLE & 5. FUNDING NUMBERS
\end{tabular}

Recycled Glass Fiber Reinforced Polymer Composites Incorporated in Mortar for

Improved Mechanical Performance

\section{AUTHOR(S)}

Harry Rodin III, Somayeh Nassiri, Karl Englund, Osama Fakron, Hui Li

Department of Civil and Environmental Engineering

Washington State University

7. PERFORMING ORGANIZATION NAME(S) AND ADDRESS(ES)

Center for Environmentally Sustainable Transportation in Cold Climates

University of Alaska Fairbanks

Duckering Building Room 245

5. FUNDING NUMBERS

P.O. Box 755900

Fairbanks, AK 99775-5900

9. SPONSORING/MONITORING AGENCY NAME(S) AND ADDRESS(ES)

U.S. Department of Transportation

1200 New Jersey Avenue SE

Washington, D.C. 20590

11. SUPPLEMENTARY NOTES

12a. DISTRIBUTION / AVAILABILITY STATEMENT

No restrictions

13. ABSTRACT (Maximum 200 words)

Glass fiber reinforced polymer (GFRP) recycled from retired wind turbines was implemented in mortar as a volumetric replacement of sand during the two phases of this study. In Phase I, the mechanically refined GFRP particle sizes were sieved for four size groups to find the optimum size. In Phase II, the select GFRP size group was incorporated at three different volumetric replacements of sand to identify the optimum replacement content. The mixtures were tested for compressive strength, flexural strength, toughness, and the potential for alkali-silicate reaction. Incorporation of GFRP in mortar proves promising in improving flexural strength and toughness in fiber-like shapes and $1-3 \%$ volumetric fractions.

14- KEYWORDS:

Mortar; glass fiber reinforced polymer (GFRP); compressive strength; flexural strength; toughness; alkali-silicate reaction (ASR)

17. SECURITY CLASSIFICATION OF REPORT

Unclassified
18. SECURITY CLASSIFICATION OF THIS PAGE

Unclassified
19. SECURITY CLASSIFICATION OF ABSTRACT

Unclassified
15. NUMBER OF PAGES

43

16. PRICE CODE

20. LIMITATION OF ABSTRACT

N/A 


\section{Disclaimer}

This document is disseminated under the sponsorship of the U.S. Department of Transportation in the interest of information exchange. The U.S. Government assumes no liability for use of the information contained in this document. The U.S. Government does not endorse products or manufacturers. Trademarks or manufacturers' names appear in this report only because they are considered essential to the objective of the document. Opinions and conclusions expressed or implied in the report are those of the author(s). They are not necessarily those of the funding agencies. 


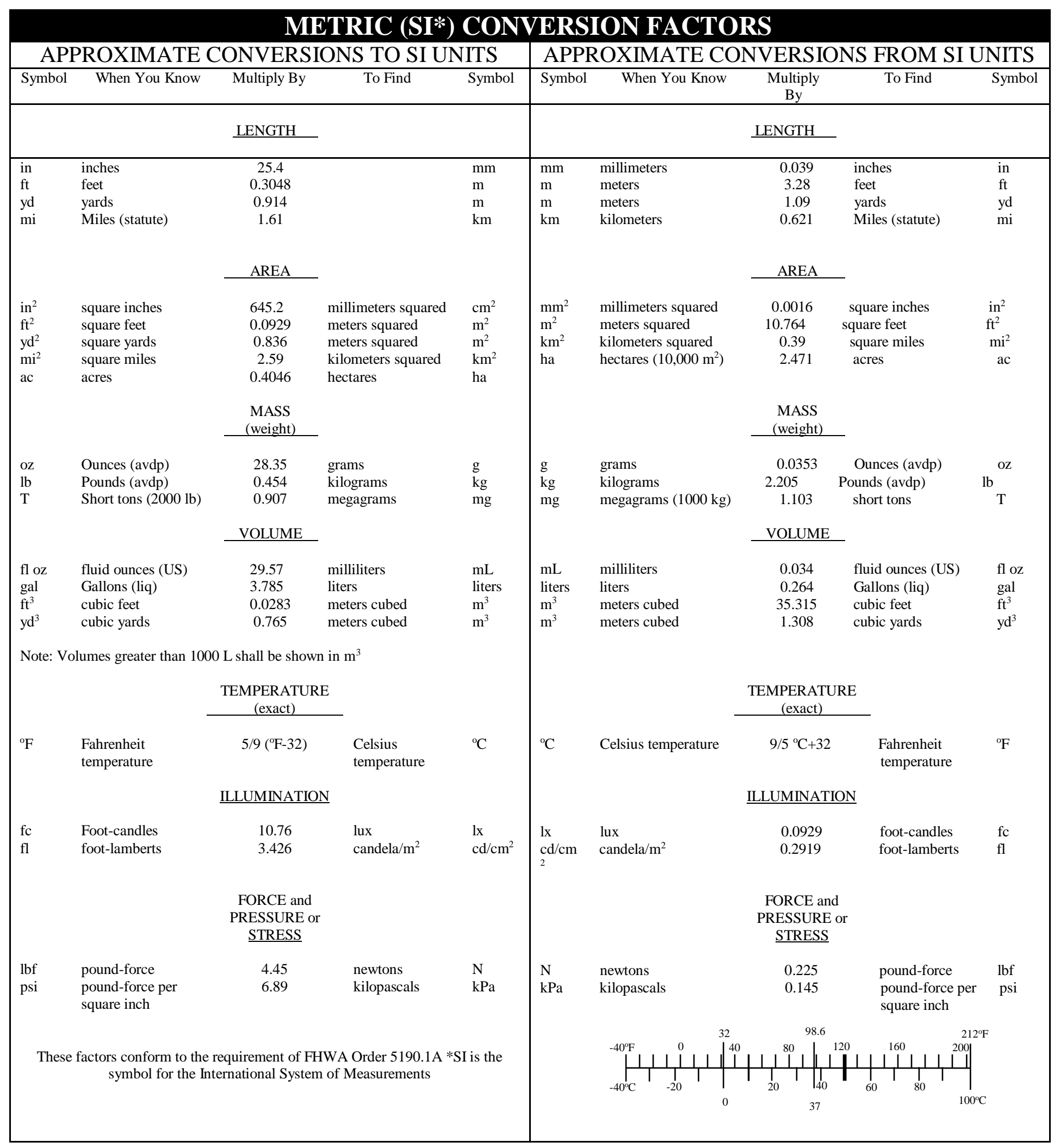




\section{Acknowledgments}

The authors are thankful to the U.S. Department of Transportation Center for Environmentally Sustainable Transportation in Cold Climate for funding this project. We are also grateful for the Global Fiberglass Solution contribution as matching funds for this study. The Ashgrove Cement Company is acknowledged for their donation of material. Thanks to Lathan Card and Jon Hatt for assistance with laboratory work. 


\section{Table of Contents}

Disclaimer i

Acknowledgments iii

List of Figures $\mathrm{v}$

List of Tables vi

Executive Summary. 7

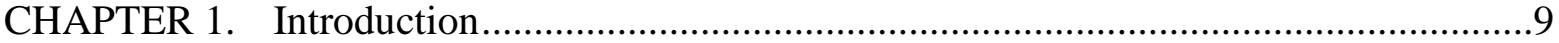

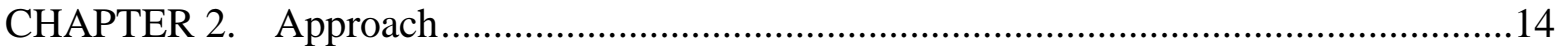

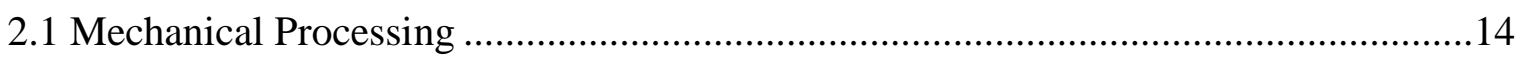

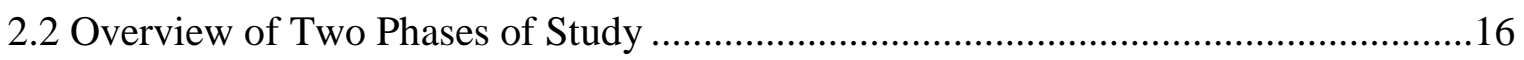

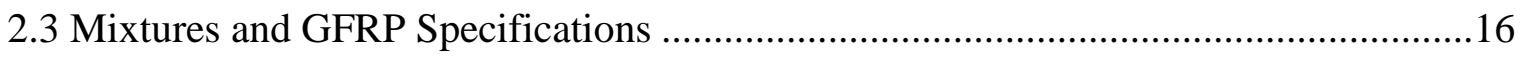

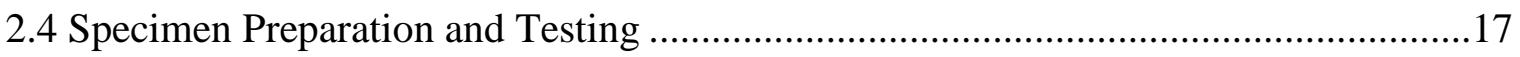

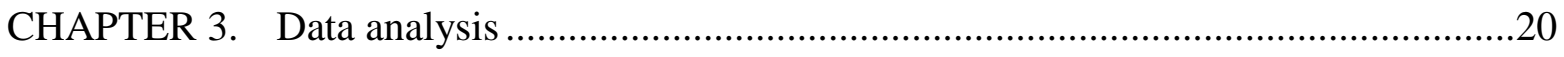

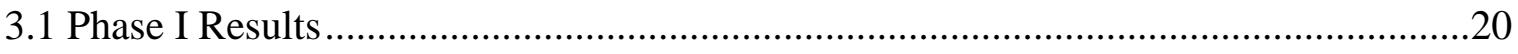

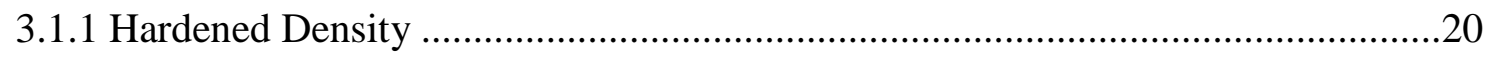

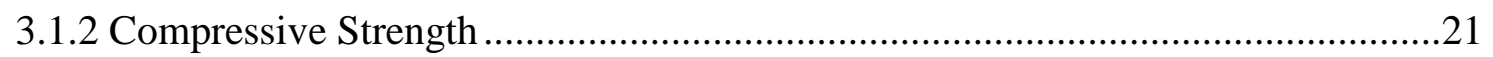

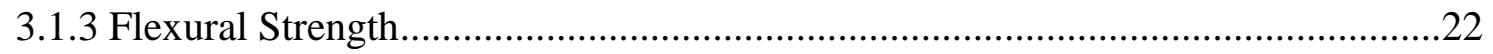

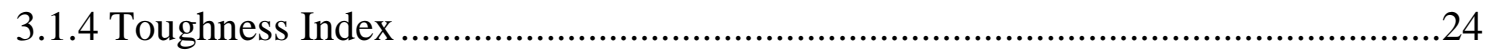

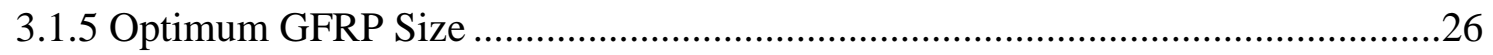

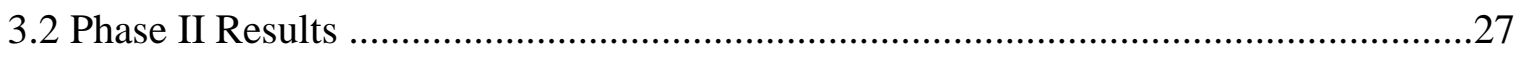

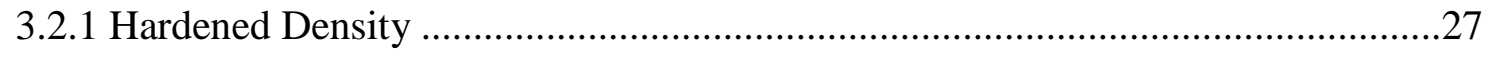

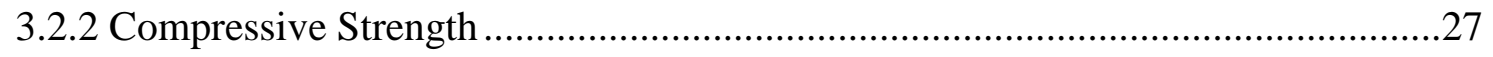

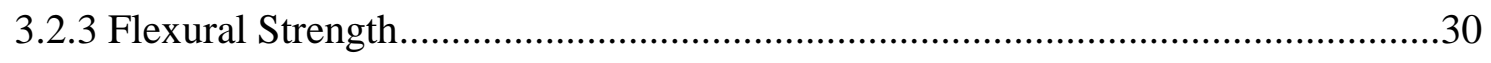

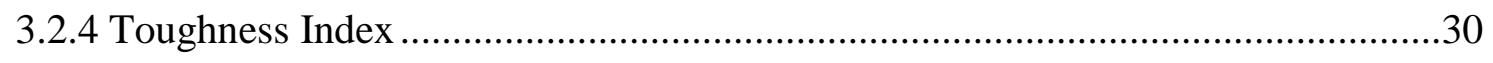

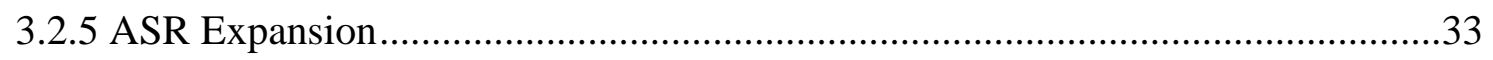

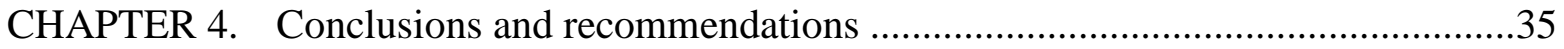

References $\quad 38$ 


\section{List of Figures}

Figure 2.1 GFRP panels (a) and GFRP sizes (b): Large (L) - upper left, Medium (M) upper right, Small (S) - lower left, Powder (P) - lower right. ........................................15

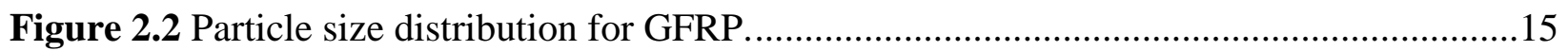

Figure 2.3 Testing for (a) compressive strength, (b) flexural strength, and (c) alkalisilicate reaction.

Figure 3.1 Compressive strength results at 7-day age during Phase I.

Figure 3.2 Images of crushed cube specimens after testing and failure for (a) Control, (b) Large, (c) Medium, (d) Small, and (e) Powder. .22

Figure 3.3 Flexural strength results at 7-day age during Phase I.

Figure 3.4 Images of fracture surfaces of prisms after testing and failure for (a) Control, (b) Large, (c) Medium, (d) Small and (e) Powder.

Figure 3.5 Example of load-deflection curve for calculating the toughness index (a) and one load-deflection curve for each mixture used during Phase I (b). The graph in (a) was recreated from ASTM C1018.

Figure 3.6 Hardened densities for each GFRP content and specimen type used in Phase II

Figure 3.7 Compressive strength results at 7-, 28- and 90-day age during Phase II.

Figure 3.8 SEM images taken from the fracture face of a broken prism at two different $500 \mu \mathrm{m}$ scales: (a) large scale and (b) small scale

Figure 3.9 Flexural strength results at 7-, 28- and 90-day age during Phase II.

Figure 3.10 One load-deflection curve at 7-, 28- and 90-day age for each mixture used during Phase II

Figure 3.11 Length-change results to identify ASR expansion in each mixture during

Phase II. 


\section{List of Tables}

Table 2.1 Mixture designs used in both phases of the study. ..............................................17

Table 3.1 Hardened densities for each mixture and specimen type used in Phase I....................20

Table 3.2 Toughness index equations and values for each mixture during Phase I. ...................26

Table 3.3 Toughness index values at 7-, 28-, and 90-day age for each mixture during

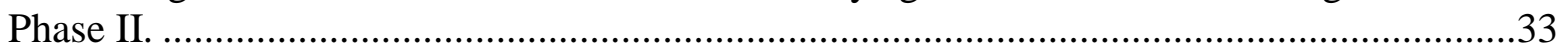




\section{Executive Summary}

This study incorporates the use of recycled glass fiber reinforced polymer (GFRP) in mortar as a volumetric replacement of sand. To understand better how GFRP would affect the properties of mortar, a feasibility study was conducted to compare different GFRP sizes and dosages. Glass fiber reinforced polymer panels were received from retired wind turbine blades and processed using a hammer mill and shredder. Once the GFRP materials were processed, the GFRP was mechanically sieved to compare different sizes.

This project had two phases. Phase I was a study of four different GFRP sizes (referred to in the report as Large, Medium, Small, Powder), classified by using sieves that the GFRP passed through or retained. Each size was used as a 3\% volumetric replacement of sand. During Phase 1, a mixture containing each GFRP size was compared with a plain mortar mixture (control). The changes in density due to the GFRP's lightness were monitored and compared with the sand. Seven-day compressive and flexural strengths were evaluated. Load deflection curves that were recorded during flexural testing were used to evaluate toughness increases caused by the GFRP addition. Based on the results of Phase I, an optimum GFRP size was selected for further investigation in Phase II.

Phase II used the optimum GFRP size at three volumetric replacements of sand $(1 \%, 3 \%$, and 5\%). During Phase II, density was compared. Compressive strength, flexural strength, and toughness were evaluated over a 90-day span. Alkali-silicate reaction (ASR) tests were performed during Phase II to test for potentially negative reactions occurring between the GFRP and cement paste. During both Phase I and II, compressive strength was tested on cubes, and flexural strength was tested on prisms. Alkali-silicate reaction tests were also performed on prism specimens. 
During Phase I, it was found that density decreased as the GFRP size decreased, which was due to the difference in specific gravity between the sand and GFRP material. During compressive strength testing, Large showed comparable strength to the control, while the other three GFRP sizes showed significant decreases in strength. Large also showed a significant increase in flexural strength, while the other GFRP sizes showed insignificant changes (both increases and decreases) compared with the control. Toughness increased as the GFRP size increased. From these results, Large was found to be the optimum size.

As expected in Phase II, the density and the compressive strength decreased as GFRP content increased, with the 5\% content showing significant decreases in compressive strength. In terms of flexural strength and toughness, both properties increased as GFRP content increased. During ASR testing, no negative expansion was recorded. In Phase II of the study, 3\% was found to be the optimum GFRP content.

Based on the results from Phase I and II, the Large GFRP size implemented as a 3\% volumetric replacement of sand yielded optimum results. This conclusion is based on comparable compressive strength as well as increases in flexural strength and toughness. The ASR expansion test results were positive.

This feasibility study showed promising results for implementing GFRP in mortar and should be expanded further for implementation of this type of reinforcement in cement-based material. Future research will implement GFRP material in concrete at a larger scale. Although some sizes and volumetric contents did not yield optimum results in mortar, it would be beneficial to test all of types at a larger scale and in a wider range of mixtures. 


\section{CHAPTER 1. INTRODUCTION}

In the last two decades, glass-based materials in the form of powder or fibers from recycled bottles and other products, and recently, recycled glass fiber reinforced polymer (GFRP) composites from end-of-life products or industrial waste have been incorporated in cement-based mixtures in various proof-of-concept studies (Correia et al. 2011, Arulrajah et al. 2015, Shayan and Xu 2006). Such incorporation offers an environmentally and economically beneficial reuse application for various mounting waste piles, diverting materials from landfill sites, and provides an opportunity to conserve the staggering stockpile of raw materials used globally each year to produce concrete (Shi and Zheng 2007). The use of glass powder has reduced carbon dioxide and nitrogen oxide emissions due to the reduced quantity of cement needed (Shi and Zheng 2007). Case studies of glass waste reuse in cement-based materials are abundant in the literature. In the following sections, the various effects of recycled glass-based materials on the properties of cement-based mixtures are discussed in clusters around individual properties.

Lightweight concrete is favored in some cases because of reduction in the material's dead load. Glass, which is relatively light compared with the raw materials used to manufacture concrete, can reduce overall density $(\rho)$ when implemented as a replacement of concrete constituents. Density can be an indicator of how well the added material affects compaction. Lower $\rho$ of $1-11 \%$ was reported for all glass contents ranging from 5-50\% replacement of fine aggregate with crushed glass sand or waste glass powder (Shayan and Xu 2006, Asokan et al. 2009). Two studies reported reduced $\rho$ by implementing crushed glass bottles and jars in mortar in large replacement amounts of coarse or fine aggregate ranging from 10-60\%, but both studies 
only found reductions of less than $1 \%$ in reported density (Topcu and Canbaz 2004, Ismail and Al-Hashmi 2009).

Implementing glass waste in concrete has an influence on the mechanical properties of concrete. Compressive strength $\left(f^{\prime} c\right)$ does not always improve when recycled materials are used, commonly because of the added weak linkages between the paste and other constituents. One study showed that $f^{\prime} c$ decreased 19-47\% when glass fibers were implemented at 5-20\% replacement of fines (Correia et al. 2011). Another study that used recycled wind turbine blades as $1 / 2$-inch and 1 -inch composite aggregate found $f^{\prime} c$ decreases of $22-45 \%$ for $25-50 \%$ replacement of coarse aggregate. The author noted that the smooth edges of the glass aggregate did not bond well with the cement paste, based on fractures that occurred along the composite aggregate surfaces (Fox 2016). A few other studies reported large decreases in $f^{\prime} c$ ranging from 10-68\% when using glass waste to replace fine aggregate (Shayan and $\mathrm{Xu} 2006$, Asokan et al. 2009, Topcu and Canbaz 2004). In one study, a spherical glass waste material was suggested because it may produce higher strength results (Topcu and Canbaz 2004). Conversely, one study used powder and fibers at 5\% and 15\% replacement and reported $f^{\prime} c$ increases of $14 \%$ and $6 \%$, (Asokan et al. 2010). Other authors found a f'c increase of $4 \%$ when implementing crushed glass bottles and jars to replace sand but noted a $f^{\prime} c$ decrease at lower implementation percentages. Ismail and Al-Hashmi (2009) reported that variation in results could be due to inadequate bonding of the cement paste and glass aggregate. One study used plain and grooved fiber reinforced polymer (FRP) needles (6 mm diameter and $100 \mathrm{~mm}$ long), replacing coarse aggregate at 5\% and 10\% (Yazdanbakhsh et al. 2018). The grooved needles, each of which had notches along the edge to improve bonding, showed a compressive strength increase of up to $7 \%$, while the plain needles showed a compressive strength decrease of $2 \%$. A similar study used 
FRP plain needles and chopped FRP rebar at 5\% and 10\% replacement of coarse aggregate (Yazdanbakhsh et al. 2017). Strength reductions of 3-9\% were recorded for the mixtures. The authors noted that the cylindrical shape of the FRP rebar might have had difficulty bonding to the cement paste compared with the angular shape of coarse aggregate. In summary, based on the literature reviewed, percentages of glass waste below $10 \%$ may result in minimal reductions or improvements in $f^{\prime} c$.

Flexural strength or the modulus of rupture (MR) is another important mechanical property required for concrete bending members such as slabs and beams. The implementation of glass waste may improve the MR, especially if glass fibers are able to bridge microfractures, transfer stresses across small cracks, and mitigate formation of larger cracks. Flexural strength increases of up to $11 \%$ were found in one study that implemented powdered glass bottles and jars at 10-20\% replacement of fine aggregate (Ismail and Al-Hashmi 2009). Other researchers found that MR increases 58\% when using glass fibers to replace fines at 5\% in panels (Asokan et al. 2009). As opposed to the two studies just mentioned, replacement of fine aggregate at 20-100\% with cathode ray tube glass resulted in a 3-39\% reduction in MR; the reduction was thought to be caused by poor bonding between the glass and cement paste (Ling and Poon 2011, Ling and Poon 2012). One study replaced fine aggregate at $25-100 \%$ with crushed funnel glass and saw reductions of MR up to 40\% (Ling et al. 2012). A group of researchers using 10-30\% fine recycled glass found that as glass content increased, benefits decreased compared with the control mixture (Arulrajah et al. 2015). Yazdanbakhsh et al. (2018), in the study that used plain and grooved needles, found that MR decreased for all mixtures except the grooved needles implemented at 5\% (as coarse aggregate replacement). Some authors witnessed differences in results when crushed glass replacing $15 \%$ and $45 \%$ of coarse aggregate increased MR but 
reduced the strength when replacing $30 \%$ and $60 \%$ of coarse aggregate. The authors noted that the reduction in strength was most likely due to an inhomogeneous distribution of the glass due to its round geometry (Topcu and Canbaz 2004). Implementation of glass waste in concrete can result in MR increases, as seen in some studies just cited, but has the potential to negatively influence flexural strength, depending on the recycled material's size and bond with the cement paste.

One concern with using glass-based waste in concrete is the potential to develop an internal expansive gel over time due to alkali-silicate reaction (ASR), which can cause cracking and damage. One study found that cathode ray tube glass and crushed beverage glass show more ASR expansion after 28 days compared with the control mixture (Hui and Sun, 2011). The authors noted that at the 14-day mark, all specimens except for one glass mixture were under the acceptable limit of $0.1 \%$ specified in ASTM C1260 (2014). Other researchers also found that the use of cathode ray tube glass resulted in greater ASR reaction compared with a plain mixture when following procedures in ASTM C1260 (Ling and Poon, 2011). Another study following the ASTM C1260 test procedure showed that using colored soda bottles as glass waste resulted in less ASR expansion than the control, but all of the results were greater than the limit evaluated of $0.2 \%$ after 14 days (Topcu and Canbaz 2004). Based on the literature review, glass waste implemented in concrete can cause ASR expansion and therefore should be investigated.

In this study, recycled GFRP composites from end-of-life wind turbine blades were implemented as a replacement for sand in mortar. The GFRP was processed into various graded classes of fiber and powder-like materials before implementation in mortar. The purpose of this feasibility study was to gain an initial understanding of the varied influences of GFRP when implemented in mortar, in various size groups and then replacement contents of the recycled 
materials. Based on the literature review, density, strengths, toughness, and volumetric instability were monitored and are reported for the mortar mixtures. To test all of these aspects, we completed the following tasks:

- Monitored how GFRP changes the density of the mixture on hardened samples.

- Evaluated strength changes at 7-, 28-, and 90-day ages in both compression and flexural loading.

- Monitored toughness to evaluate the influence of GFRP on post-peak behavior.

- Assessed the potential development of ASR gel and the resulting expansion in the mortar. 


\section{CHAPTER 2. APPROACH}

\section{$\underline{2.1 \text { Mechanical Processing }}$}

The glass fiber reinforced polymer (GFRP) used in this study was rectangular panels from end-of-life wind turbine blades. The mechanical recycling process starts with the panels cut into small rectangular pieces before being fed into a shredder and hammer mill. Several cut panels before the shredding process are shown in Figure 2.1(a). The result of the shredding and milling processes is a mixture of fines, fiber-like, and plate/flake-like materials. The particle size distribution for the material after grinding is shown in Figure 2.1(b)

This material was then placed in a sieve shake table to process the different GFRP size groups. The larger sieves resulted in fiber-like strands, while the smallest sieves resulted in glass powder (Figure 2.1(b). Four different size groups were sieved and designated letter names (see table in Figure 2.2(a). Each group size besides the powder was evaluated using image analysis to find its respective aspect ratio. A MATLAB code was developed to establish the aspect ratio of each GFRP size group by analyzing its respective binary images. The aspect ratio data were a combination of results from four different sample images for each group size. Figure 2.2 shows the aspect ratio range for each size in terms of the percentage content of the overall sample evaluated. The erroneous large aspect ratios are most likely due to clumping of GFRP, which cannot be separated into individual strands by the code. The composition of the GFRP material, which was evaluated using thermogravimetric analysis (TGA), was found to be $57 \%$ fiberglass and $43 \%$ polyester resin. 


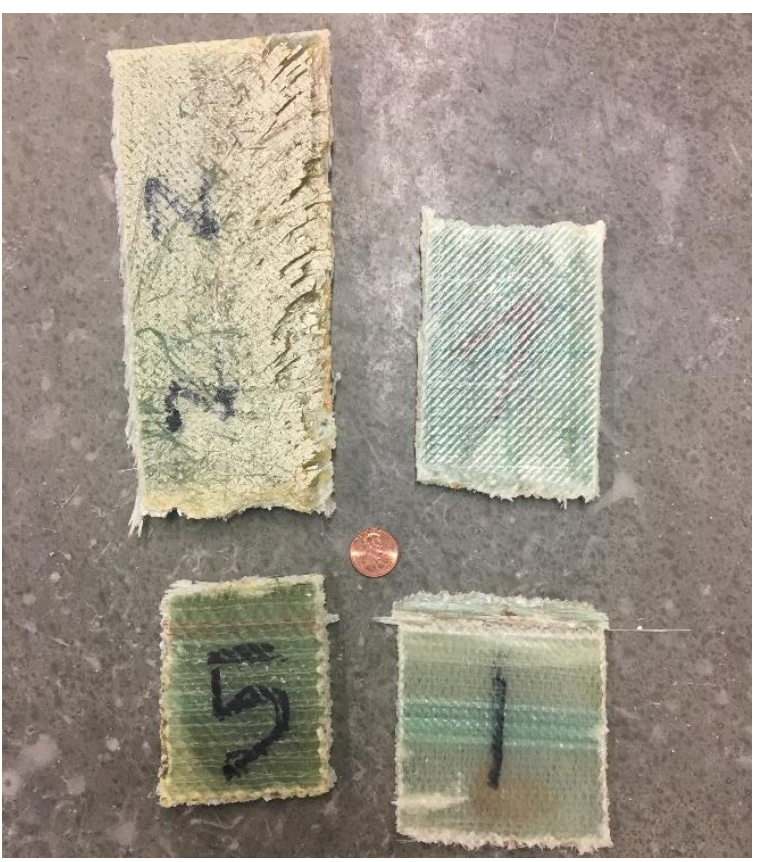

(a)

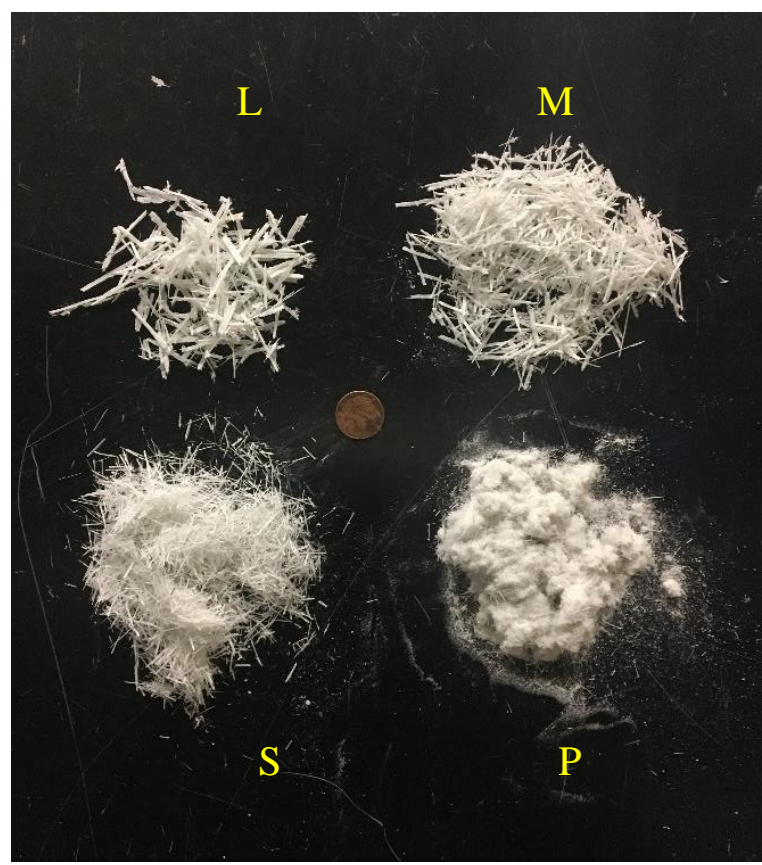

(b)

Figure 2.1 GFRP panels (a) and GFRP sizes (b): Large (L) - upper left, Medium (M) - upper right, Small (S) - lower left, Powder (P) - lower right.

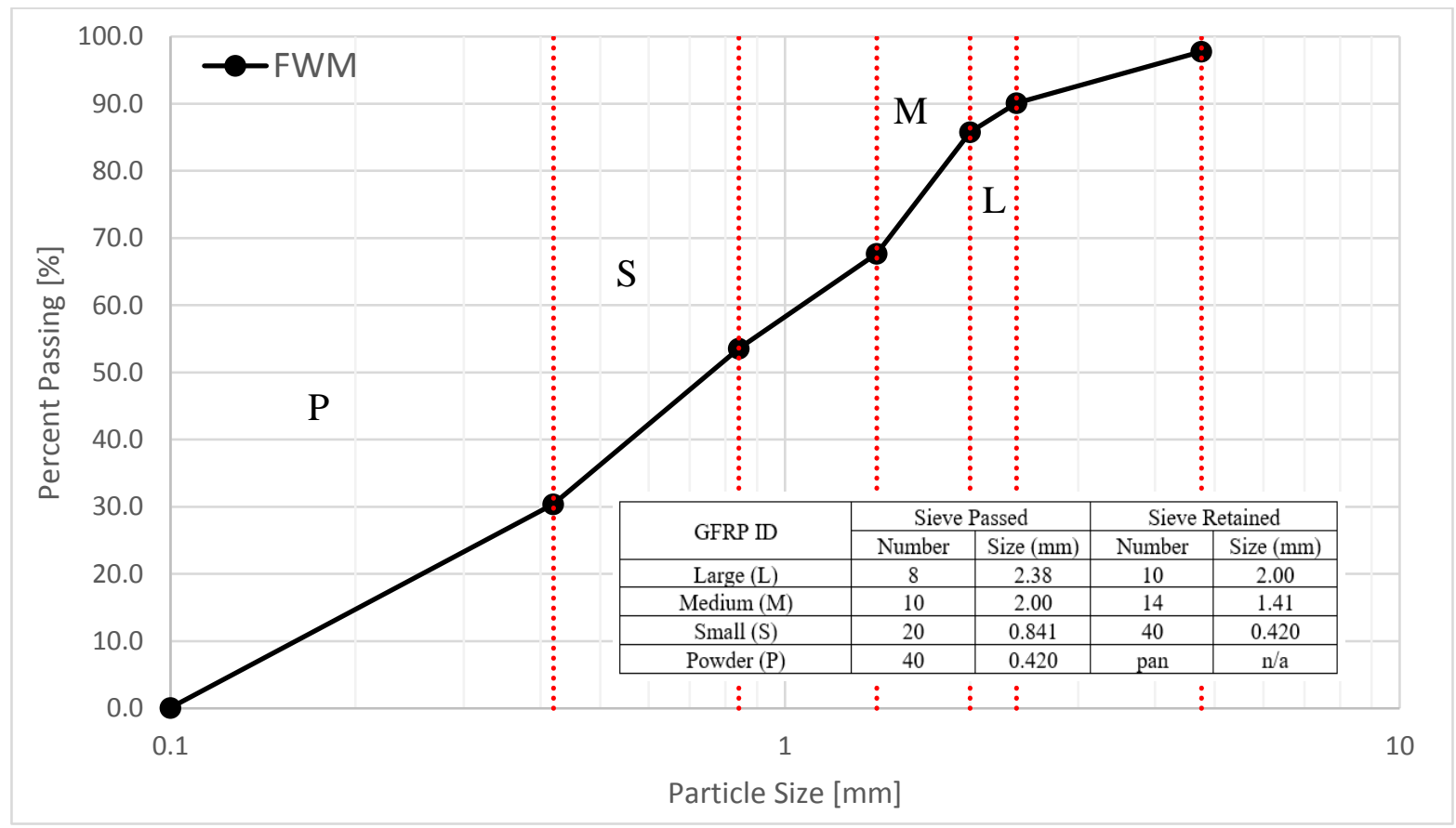

Figure 2.2 Particle size distribution for GFRP. 


\subsection{Overview of Two Phases of Study}

This experimental study was performed in two phases. In Phase I, our goal was to find the best performing GFRP size group. All four size groups of GFRP replaced sand at 3\% by volume for a consistent size comparison. Compressive strength $\left(f^{\prime} c\right)$, modulus of rupture (MR), and toughness index (TI) were evaluated to find the best performing GFRP size group.

In Phase II we compared different volume percentages of GFRP using the most effective size group identified in Phase I. Glass fiber reinforced polymer was implemented in the mixture design at $1 \%, 3 \%$, and $5 \%$ replacement of sand by volume.

\section{$\underline{2.3 \text { Mixtures and GFRP Specifications }}$}

Lane Mt. Company Sand was used in the mortar mixtures implemented, and Type I/II Portland cement from Ashgrove Cement Company was used. For Phase I, we used a water-tocement ratio (w/c) of 0.35 . The mixture design for this phase of the project is given in Table 2.1. In Phase II, the w/c was raised to 0.40 to create a more workable mixture while keeping the other proportioning the same as that in Phase I (Table 2.1). The specific gravity of the GFRP, which was tested on the panels prior to grinding, was found to be 1.76 per ASTM C127 (2015). 
Table 2.1 Mixture designs used in both phases of the study.

\begin{tabular}{|c|c|c|c|c|c|c|c|}
\hline \multirow{2}{*}{$\begin{array}{c}\text { Mixture } \\
\text { ID }\end{array}$} & \multirow{2}{*}{$\begin{array}{c}\text { Project } \\
\text { Phase }\end{array}$} & \multirow{2}{*}{ GFRP ID } & \multirow{2}{*}{$\begin{array}{c}\text { GFRP } \\
\text { Volume } \\
\text { Percentage }\end{array}$} & \multicolumn{4}{|c|}{ Proportions $\left(\mathrm{kg} / \mathrm{m}^{3}\right)$} \\
\hline & & & & Cement & Water & Sand & GFRP \\
\hline Control & \multirow{5}{*}{ I } & not used & 0 & 674 & 236 & 1,418 & 0 \\
\hline Large & & $\mathrm{L}$ & \multirow{4}{*}{3} & \multirow{4}{*}{674} & \multirow{4}{*}{236} & \multirow{4}{*}{1,340} & \multirow{4}{*}{53} \\
\hline Medium & & $\mathrm{M}$ & & & & & \\
\hline Small & & $\mathrm{S}$ & & & & & \\
\hline Powder & & $\mathrm{P}$ & & & & & \\
\hline Control & \multirow{4}{*}{ II } & not used & 0 & \multirow{4}{*}{674} & \multirow{4}{*}{269} & 1,418 & 0 \\
\hline L1 & & \multirow{3}{*}{$\mathrm{L}$} & 1 & & & 1,392 & 18 \\
\hline L3 & & & 3 & & & 1,340 & 53 \\
\hline L5 & & & 5 & & & 1,288 & 88 \\
\hline
\end{tabular}

Note: Admixture Master Glenium 1466 was implemented in each mixture at $2.67 \mathrm{~kg}$ per cubic meter.

\subsection{Specimen Preparation and Testing}

Specimens were cast per specifications in ASTM C305 (2014). The specimens were made using a standard bench top mixer. The cement and water were added to the bowl first, and the sand was added during mixing. For the mixtures that contained GFRP, the GFRP was added after the cement. Fifty-millimeter cubes were used as $f^{\prime} c$ specimens and were tampered consistently over the surface of the specimen during two lifts. Flexure prisms $40 \times 40 \times 160 \mathrm{~mm}$ were also tampered evenly over the specimen surface and cast in two lifts. Alkali-silicate reaction prisms were cast in $50 \times 50 \times 285 \mathrm{~mm}$ molds with metal studs placed at each end per ASTM C1260 (2014), following the same compaction procedures as the MR beams. All specimens were compacted using a shake table, hit on the sides with a rubber mallet after each lift, and then finished with a trowel on the surface. Compressive and flexural strength specimens were demolded after 24 hours and placed in a fog room at $98 \%$ relative humidity and $23^{\circ} \mathrm{C}$ 
temperature. The ASR specimens were demolded after 24 hours. An initial reading was taken, and the specimens were then placed in a water bath at $80^{\circ} \mathrm{C}$ for 24 hours before the zero reading was taken. After the zero reading was taken, the prisms were placed in a sodium hydroxide solution at a concentration of 40 grams/mol of water and stayed in this solution for the remainder of the test.

The $\rho$ of each specimen was calculated using the dry mass and dimensions of each specimen after demolding. Each dimension used was an average of two caliper measurements. The volume of each specimen was calculated, and then the dry mass was divided by the volume to find the density. Compressive strength tests were completed per ASTM C109 (2016) at a load rate of 890 to 1,112 newtons/second. Flexural strength tests were run at a load rate of 0.15 millimeters/minute in accordance with ASTM C348 (2014). During Phase I, all tests performed were at 7-day age. For Phase II, both $f^{\prime} c$ and MR were tested at 7-, 28-, and 90-day age. During MR testing, load-deflection curves were recorded to evaluate post-peak performance in terms of toughness using ASTM C1018 (1997). This test standard was used due to the small size of the specimens tested. The ASR prisms were tested using a standard-length change comparator at specific time intervals from 4 to 35 days following the zero reading during Phase II. All recorded test results were an average of three specimens tested. Each test performed is shown in Figure 2.3 . 


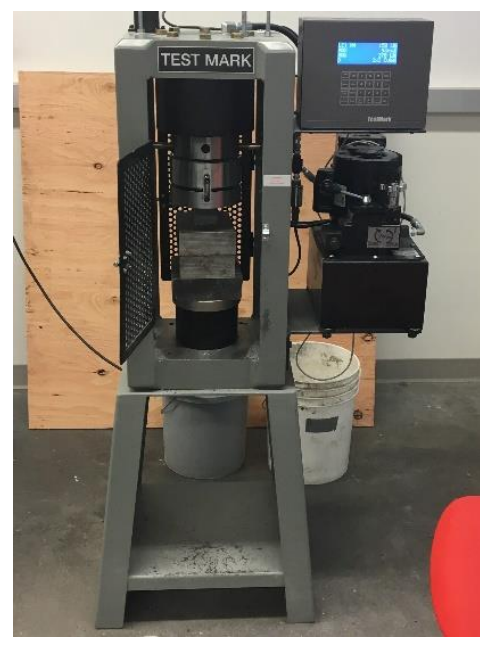

(a)

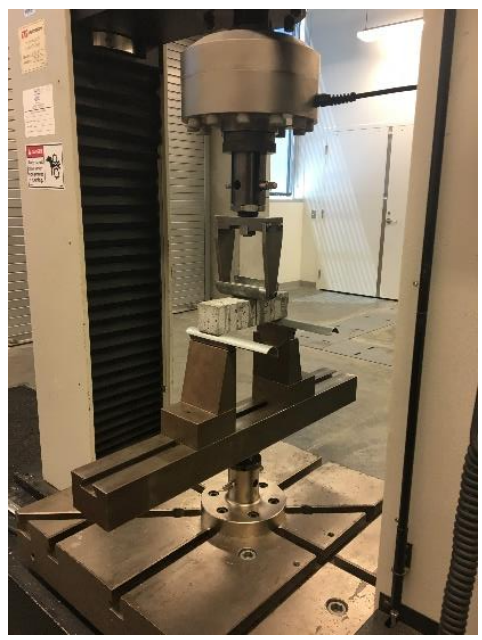

(b)

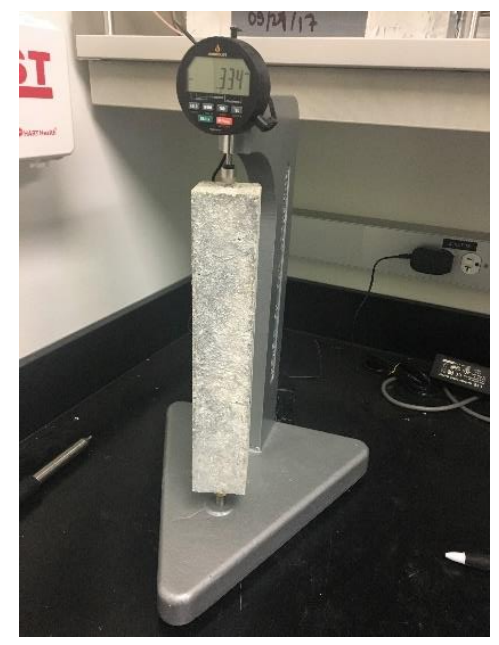

(c)

Figure 2.3 Testing for (a) compressive strength, (b) flexural strength, and (c) alkali-silicate reaction. 


\section{CHAPTER 3. DATA ANALYSIS}

\section{$\underline{3.1 \text { Phase I Results }}$}

\subsubsection{Hardened Density}

The replacement of sand with GFRP can have a lightening effect when implemented in mortar due to the GFRP's lower specific gravity (1.76) compared with sand (2.6). The average density of each mixture design can be seen in Table 3.1, which shows that each of the GFRP mixtures resulted in lighter specimens. Based on the results shown in Table 3.1, as the GFRP became smaller, the specimens became lighter due to the ease of compaction being able to contain more GFRP in each specimen. Statistical analysis was used to evaluate the changes in density for the GFRP mixtures compared with the control, with any $P$-value less than 0.05 indicating a significant difference in the data (Table 3.1). Large showed no significant difference for cubes and was just below the threshold for prisms, while all other GFRP mixtures showed significant differences compared with the control.

Table 3.1 Hardened densities for each mixture and specimen type used in Phase I.

\begin{tabular}{|c|c|c|c|c|}
\hline \multirow{2}{*}{$\begin{array}{c}\text { Mixture ID } \\
(\text { size })\end{array}$} & \multicolumn{4}{|c|}{$\begin{array}{c}\text { Average of Three Hardened Density }\left(\mathrm{kg} / \mathrm{m}^{3}\right) \\
\text { and the Standard Deviations }\left(\mathrm{kg} / \mathrm{m}^{3}\right)\end{array}$} \\
\cline { 2 - 5 } & $\begin{array}{c}\text { Cubes } \\
(\text { P-value })\end{array}$ & Std. Dev. & $\begin{array}{c}\text { Prisms } \\
(\text { P-value })\end{array}$ & Std. Dev. \\
\hline Control & 2,018 & 32 & 2,034 & 32 \\
\hline Large & $2,002(0.362)$ & 34 & $1,954(0.049)$ & 27 \\
\hline Medium & $1,938(0.040)$ & 5 & $1,938(0.026)$ & 22 \\
\hline Small & $1,826(0.004)$ & 32 & $1,890(0.006)$ & 18 \\
\hline Powder & $1,890(0.012)$ & 26 & $1,922(0.028)$ & 5 \\
\hline
\end{tabular}




\subsubsection{Compressive Strength}

Figure 3.1 shows the $f^{\prime} c$ and standard deviation for each mixture of Phase I. For all GFRP mixtures except Large, the 7-day f'c decreased 26-41\% compared with the control, which was a statistically significant difference ( $P$-value of less than 0.05 compared with the control). The strength reduction for the smaller GFRP sizes may be due to the cement and water content not having been altered in each mixture. As the GFRP size is reduced, a larger number of elements are included in the mixture with a larger total surface area of GFRP. As the GFRP surface area increases, it may require a greater binder content to allow for complete bonding throughout the matrix. Smaller elements however, may disperse better throughout the mixture than larger elements. For the Large GFRP mixture, f'c increased by $2 \%$, which was not significantly different (see table in Figure 3.1), but larger standard deviations were recorded which may be due to the larger size of the GFRP. Negligible changes and reduction in the $f^{\prime} c$ were expected when incorporating fiber-like constituents in mortar, as was reported in the literature (Ismail and Al-Hashmi 2009, Yazdanbakhsh et al. 2017). All the GFRP resulted in cracking, with a few pieces flaking, compared with the control specimens that were crushed and shattered during failure (Figure 3.2). 


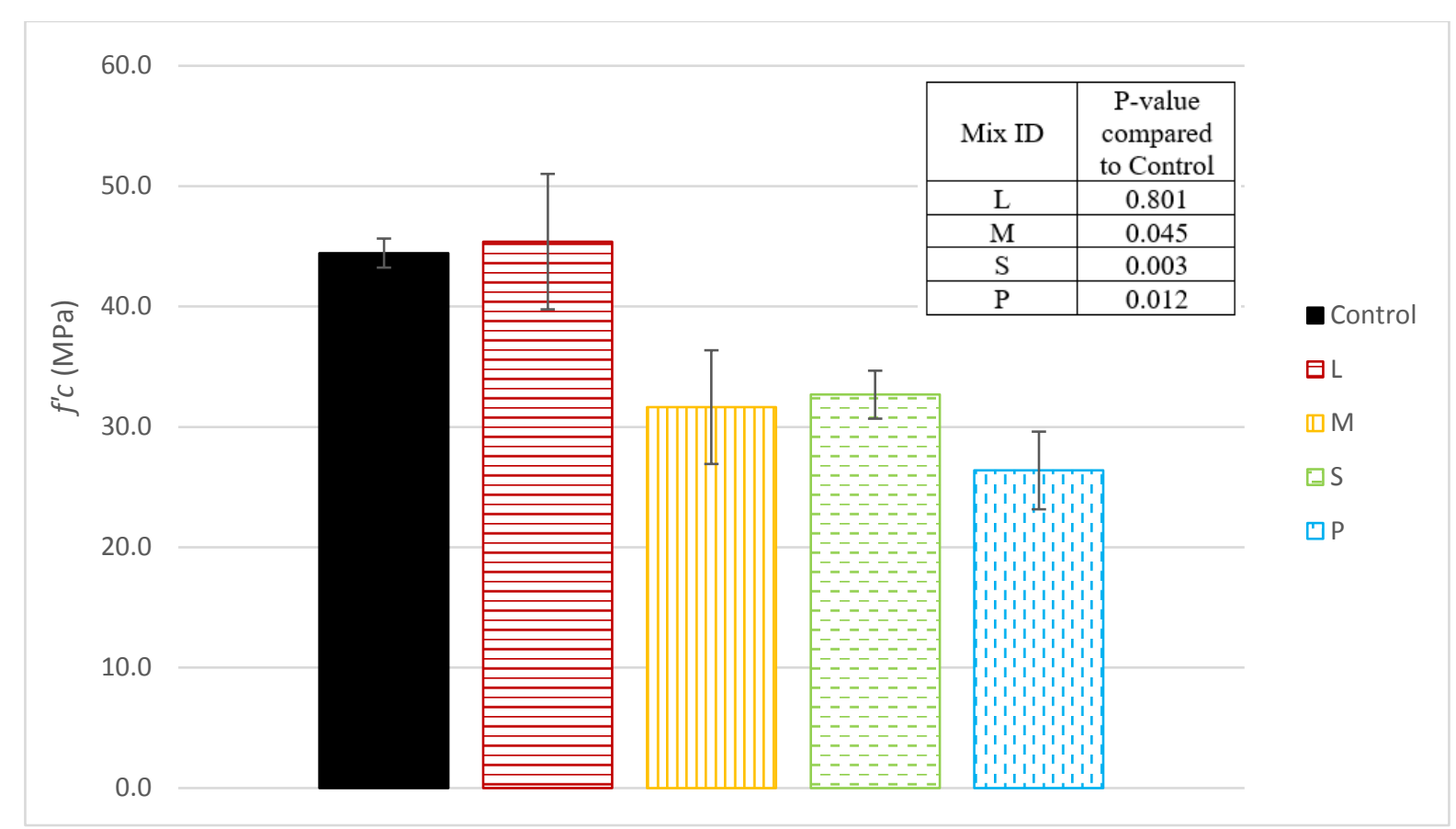

Figure 3.1 Compressive strength results at 7-day age during Phase I.

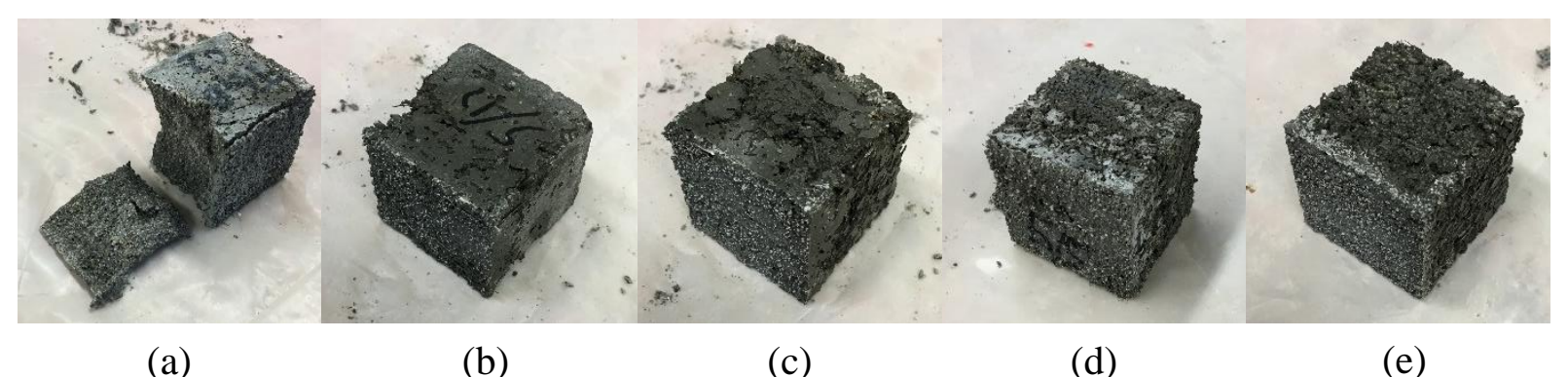

Figure 3.2 Images of crushed cube specimens after testing and failure for (a) Control, (b) Large, (c) Medium, (d) Small, and (e) Powder.

\section{$\underline{3.1 .3 \text { Flexural Strength }}$}

Based on the literature review, GFRP has the potential to increase or decrease MR depending on the type and shape of GFRP used. Seven-day average MR and the respective standard deviations are shown in Figure 3.3. A decrease in MR of 30\% resulted from using the powder-like GFRP, which agrees with results reported in the literature (Arulrajah et al. 2015, Ling et al. 2012). Medium decreased slightly, while Small actually showed a slight increase in 
strength. Large showed the greatest increase-23\%—compared with the control. These results showed that each of the fiber-like materials (Large, Medium, and Small) performed better than the fines (Powder) and the control in most cases. After statistical analysis was performed, Large was the only GFRP mixture to result in a significant difference compared with the control.

Figure 3.4 shows the MR prisms fracture surfaces after failure for each mixture during Phase I. The images show the Large GFRP strands protruding from the prisms, which helped bridge cracks during testing.

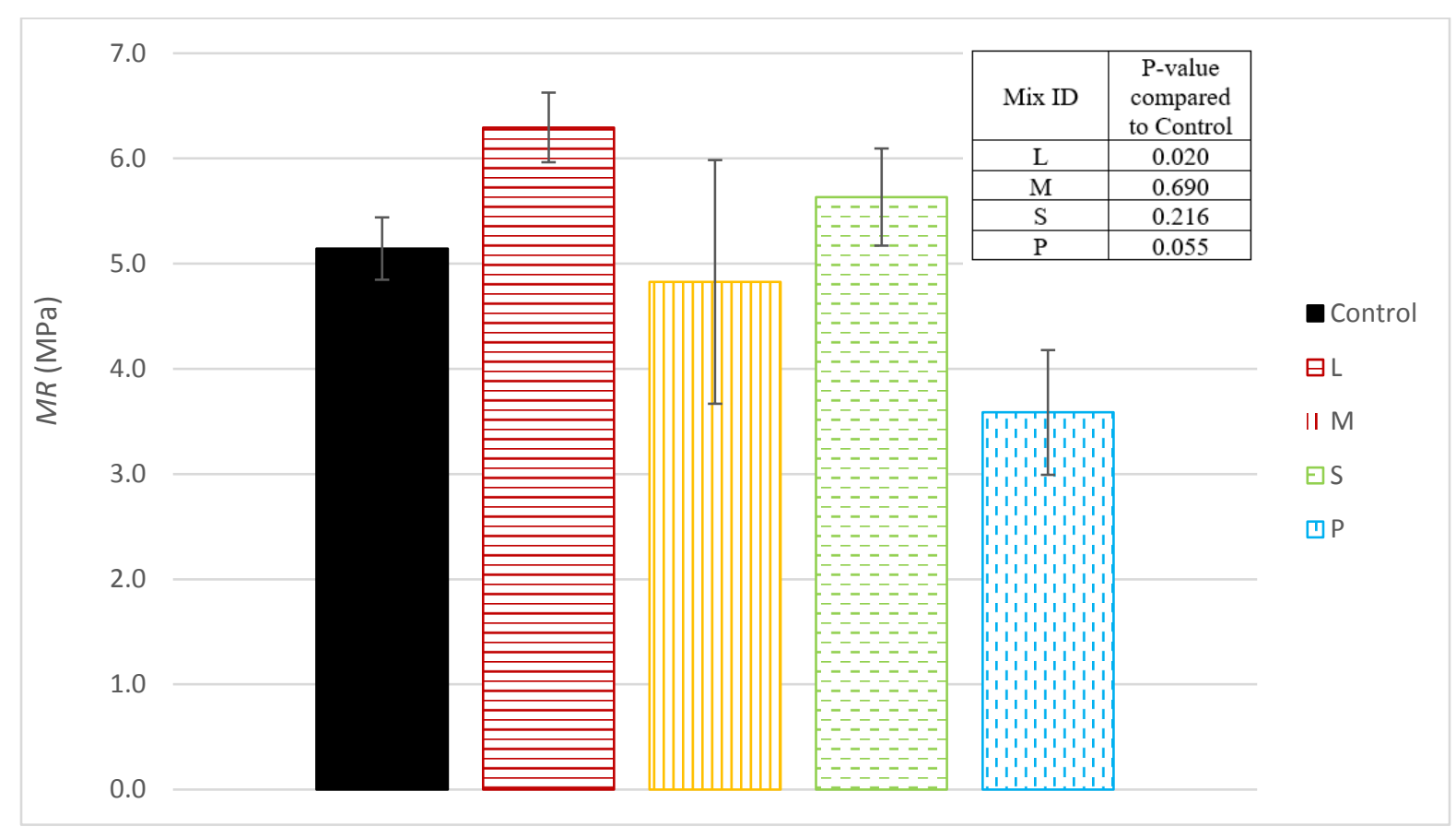

Figure 3.3 Flexural strength results at 7-day age during Phase I. 


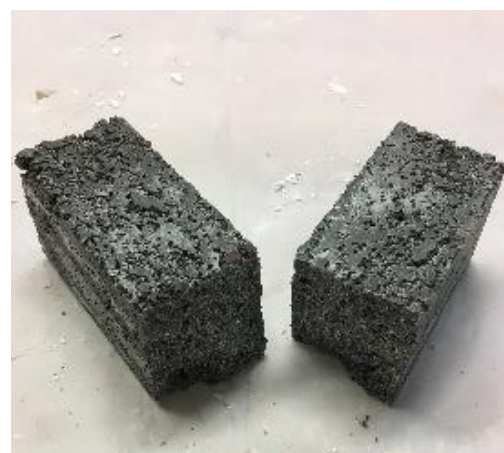

(a)

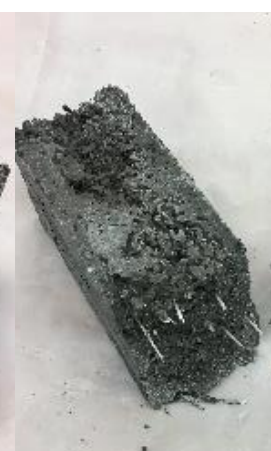

(b)

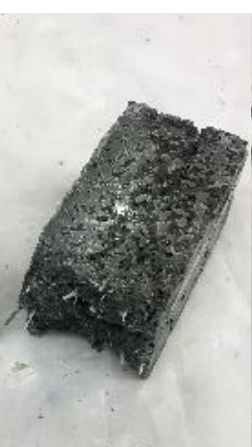

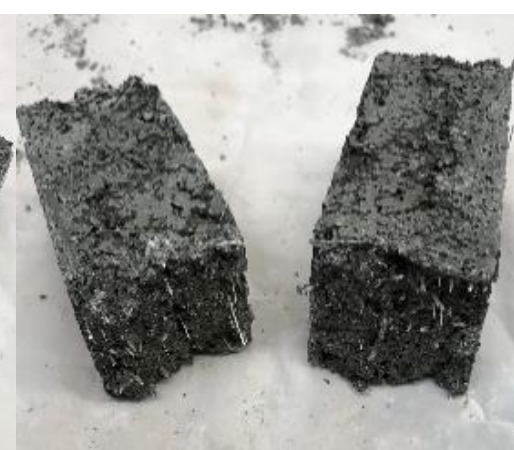

(c)

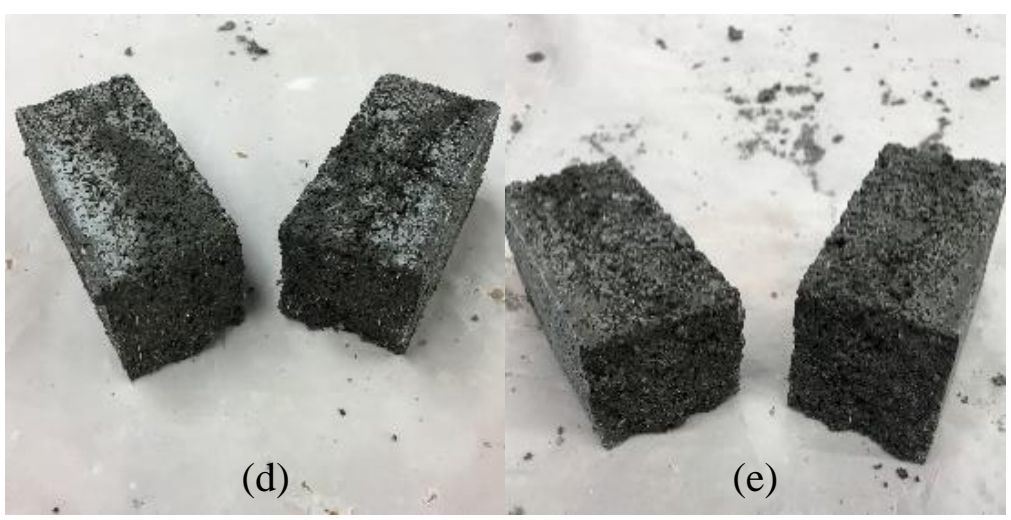

Figure 3.4 Images of fracture surfaces of prisms after testing and failure for (a) Control, (b) Large, (c) Medium, (d) Small and (e) Powder.

\subsubsection{Toughness Index}

Using load-deflection curves that were recorded during MR testing, the potential toughness increase from the use of GFRP in mortar was investigated. The toughness index (TI) calculation per ASTM 1018 (1997) is based on post-peak loading performance. For this study, the calculation method was adjusted slightly to suit the acquired data. The peak load was used to find the corresponding displacement on the load-deflection curve for TI calculation, which is marked by the first vertical line in Figure 3.5(a). The deflection at peak loading was then multiplied by factors of two, three, four and five $\left(\mathrm{I}_{2}, \mathrm{I}_{3}, \mathrm{I}_{4}\right.$, and $\left.\mathrm{I}_{5}\right)$ to find the deflections needed for each TI value. In ASTM 1018 (1997), the TI is calculated at three intervals of 3, 5.5, and 10.5 times the first crack deflection. The deflection data do not exist that far in this study, so intervals 
from 2 to 5 were picked to establish the differences in post-peak toughness. The TI values are calculated as a ratio of the areas under the curve. Figure 3.5(b) shows one load-deflection curve from each mixture during this phase of the study. The larger GFRP sizes (Large, Medium, and Small) show larger areas under the curve than that of the Powder and the control after peak loading.

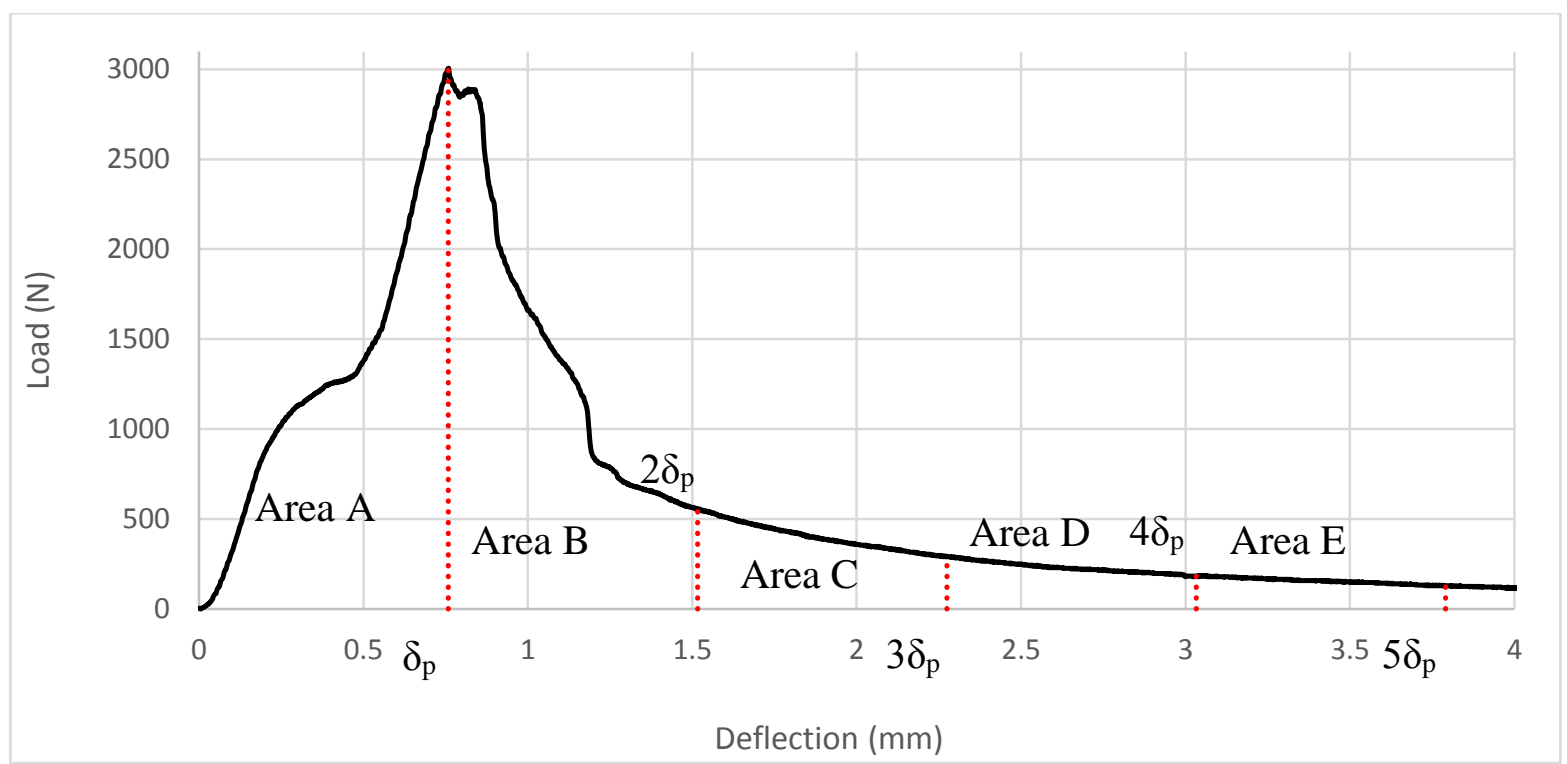

(a)

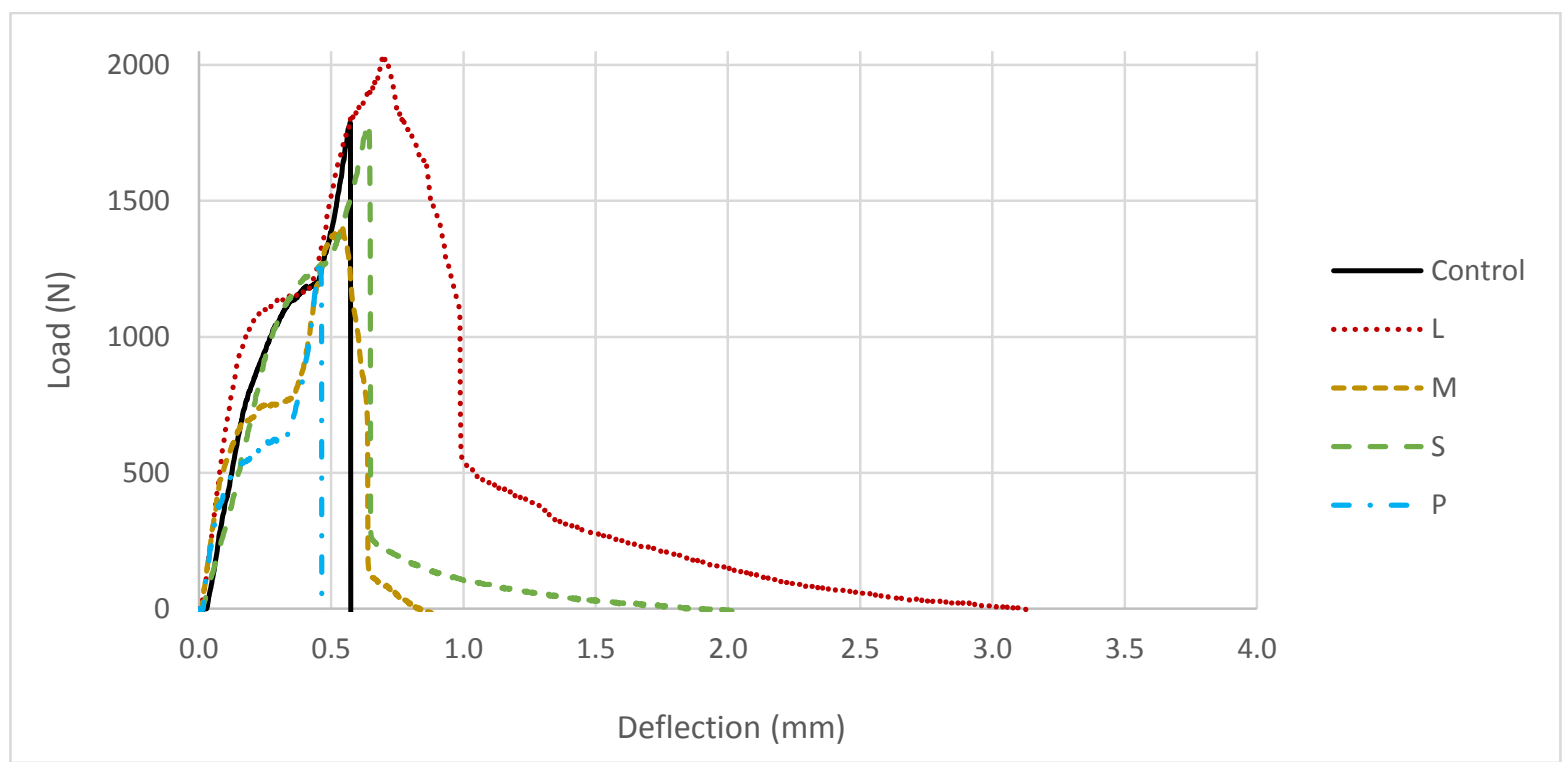

(b)

Figure 3.5 Example of load-deflection curve for calculating the toughness index (a) and one load-deflection curve for each mixture used during Phase I (b). The graph in (a) was recreated from ASTM C1018. 
The equation for each TI can be seen in Table 3.2. The corresponding index values are reported below the equations for each GFRP size; for example, $\mathrm{I}_{2}$ corresponds with the TI value at two times the peak-load deflection. Toughness index values were only evaluated if at least two of the three specimens tested resulted in an index value. In some cases, only one of the three specimens had a TI value, which was left out of the study due to the majority of specimens showing no toughness at the evaluated deflection. Specimens that had a toughness value of 1.0 were also not reported due to 1.0 being the baseline value (no toughness). As seen in Table 3.2, the control and Powder resulted in little to no post-peak toughness. Medium and Small showed toughness up to $\mathrm{I}_{3}$, while Large GFRP showed toughness all the way to the $\mathrm{I}_{5}$ value.

Table 3.2 Toughness index equations and values for each mixture during Phase I.

\begin{tabular}{|c|c|c|c|c|}
\hline \multirow{2}{*}{ Mixture ID } & \multicolumn{4}{|c|}{ Toughness Index } \\
\cline { 2 - 5 } & $I_{2}=\frac{A+B}{A}$ & $I_{3}=\frac{A+C}{A}$ & $I_{4}=\frac{A+D}{A}$ & $I_{5}=\frac{A+E}{A}$ \\
\hline Control & - & - & - & - \\
\hline $\mathrm{L}$ & 1.77 & 1.18 & 1.13 & 1.07 \\
\hline $\mathrm{M}$ & 1.79 & 1.09 & - & - \\
\hline $\mathrm{S}$ & 1.16 & 1.02 & - & - \\
\hline $\mathrm{P}$ & 1.04 & - & - & - \\
\hline
\end{tabular}

\subsubsection{Optimum GFRP Size}

Based on the results from Phase I, for the mortar mixture used in this study, Large was chosen as the optimum GFRP for the remainder of the study. This decision was based on the increase in MR while maintaining a comparable $f^{\prime} c$ to the control. Large showed larger TI values and index values farther down the spectrum than any other GFRP size. Other cementitious mixture designs need further evaluation in future studies to find the optimum mixture design for the remaining size groups of GFRP. 


\subsection{Phase II Results}

Phase II implemented the Large GFRP size in mortar at three volumetric replacements $(1 \%, 3 \%$, and $5 \%)$ of sand.

\subsubsection{Hardened Density}

The $\rho$ of the control increased slightly compared with Phase I (Figure 3.6). This increase could be due to the increase in w/c for this phase, which made for easier compaction, allowing more material into each specimen. Each of the GFRP mixtures was significantly different from the control based on statistical analysis, comparing the density values (see table in Figure 3.6). The addition of GFRP at 5\% was slightly more difficult to compact than the other dosages and most likely caused the lower densities. The higher content of lighter material may have decreased the hardened density.

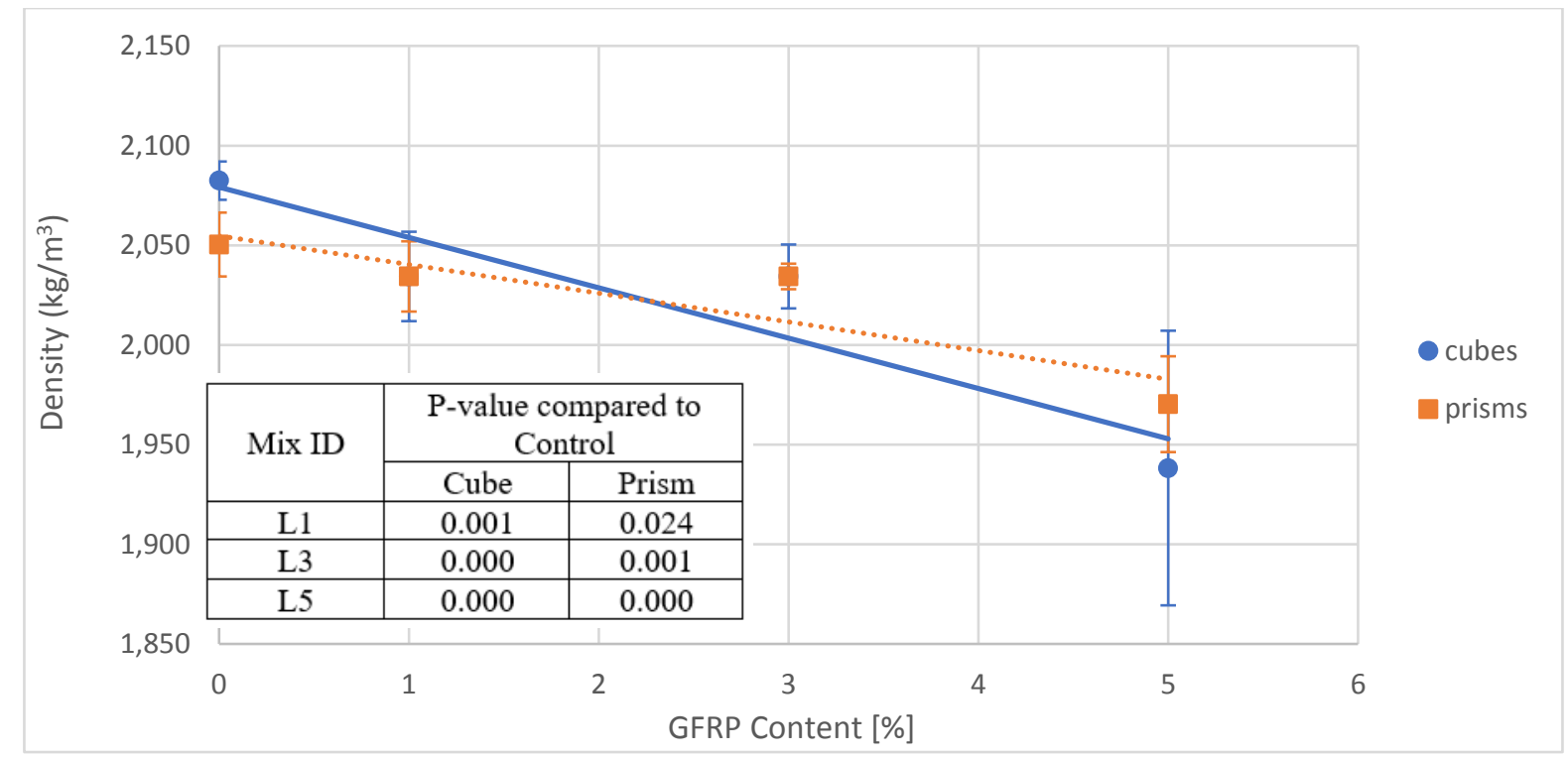

Figure 3.6 Hardened densities for each GFRP content and specimen type used in Phase II.

\subsubsection{Compressive Strength}

Compressive strength results at 7-, 28-, and 90-day age can be seen with a fitted curve in Figure 3.7; their standard deviations are marked by whisker bars. L1 resulted in higher $f^{\prime} c$ than 
the control, L3, and L5 at both 7- and 28-day testing. L3 resulted in minor decreases in $f^{\prime} c$, while L5 showed larger decreases in $f^{\prime} c$ at all ages. L3 resulted in decreases of 8\%, 9\%, and 8\% for 7-, 28-, and 90-day ages, respectively, which is comparable to decreases reported in the literature (Yazdanbakhsh et al. 2017, Yazdanbakhsh et al. 2018). Based on statistical analysis, L1 and L3 were not significantly different from the control, but L5 was significantly lower, based on $P$ values below 0.05 (see table in Figure 3.7). Control specimens shattered upon failure, while the GFRP helped keep the specimens from crumbling after failure. The values of $f^{\prime} c$ were possibly influenced by the size of the large top particle of GFRP relative to the cube dimensions used for compressive testing, which was permitted due to the feasibility nature of the study. In future phases, large cylindrical concrete specimens should be tested for f'c evaluation.

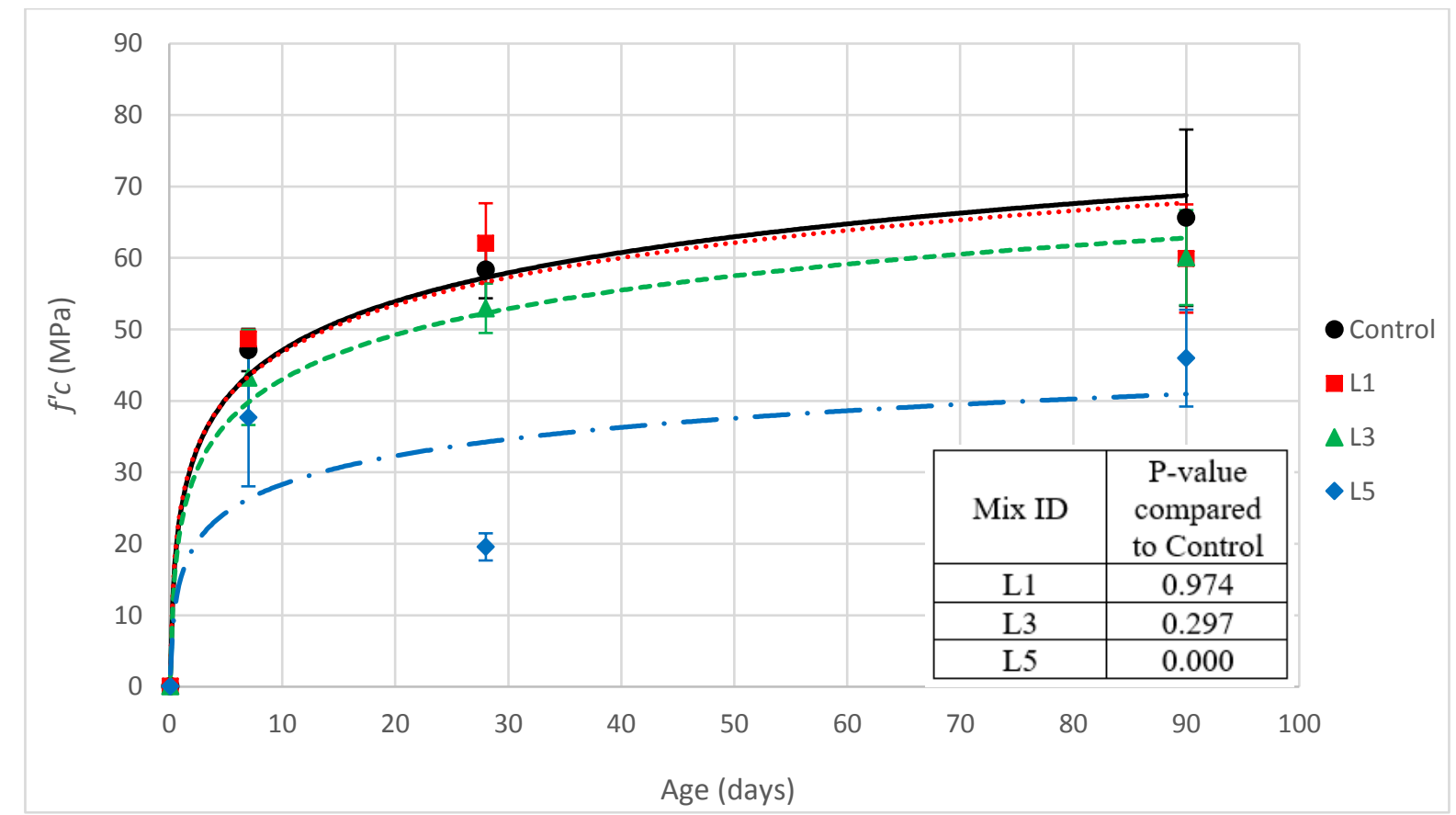

Figure 3.7 Compressive strength results at 7-, 28- and 90-day age during Phase II.

Scanning electron microscope (SEM) images were used to observe the bond and interfacial zone between the GFRP and mortar at the fracture faces after MR testing. The images, which show the interfacial zone between the two materials at two different scales, can be seen in 
Figure 3.8, where (a) shows a broader scope of the interaction between GFRP and mortar. These images show weak zones in the bond between the GFRP and cement paste, which may be the reason for the decreased $f^{\prime} c$ of the GFRP mixtures compared with the control. Figure 3.8(b) shows the interaction at a smaller scale; the cement paste can be seen nestled between the individual strands of the GFRP.

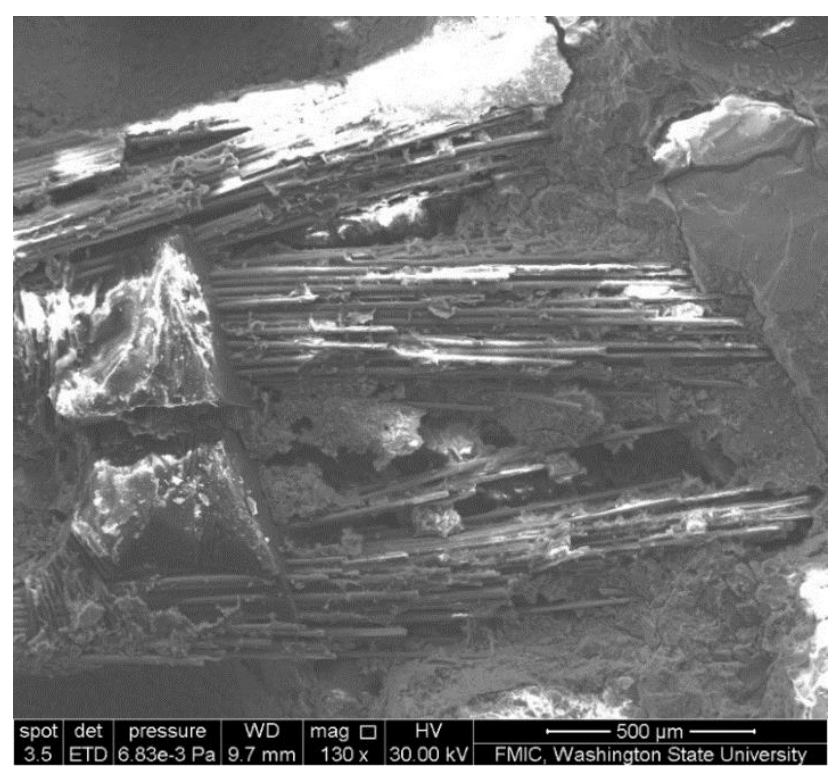

(a)

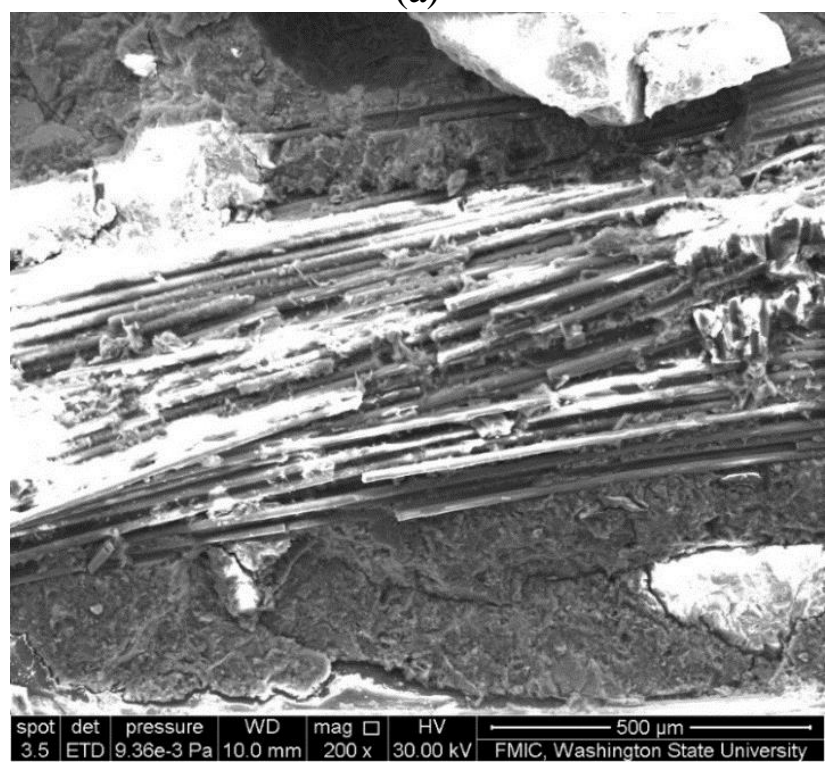

(b)

Figure 3.8 SEM images taken from the fracture face of a broken prism at two different $500 \mu \mathrm{m}$ scales: (a) large scale and (b) small scale. 


\section{$\underline{\text { 3.2.3 Flexural Strength }}$}

For most scenarios, MR increased as the GFRP content increased (Figure 3.9). All GFRP MR values increased compared with the control at all ages. L5 showed the largest increases in MR ranging from $25-36 \%$ for all test ages. L1 and L3 showed increases of $2-5 \%$ and $2-25 \%$ for all test ages, respectively. Although all GFRP mixtures increased MR, L5 was the only mixture that resulted in statistically significant differences compared with the control (see table in Figure 3.9). The increases in MR for L3 and L5 show the potential for GFRP to mitigate crack formation during testing. Although L3 showed high MR at 28-day age, the standard deviation was larger than for any other test.

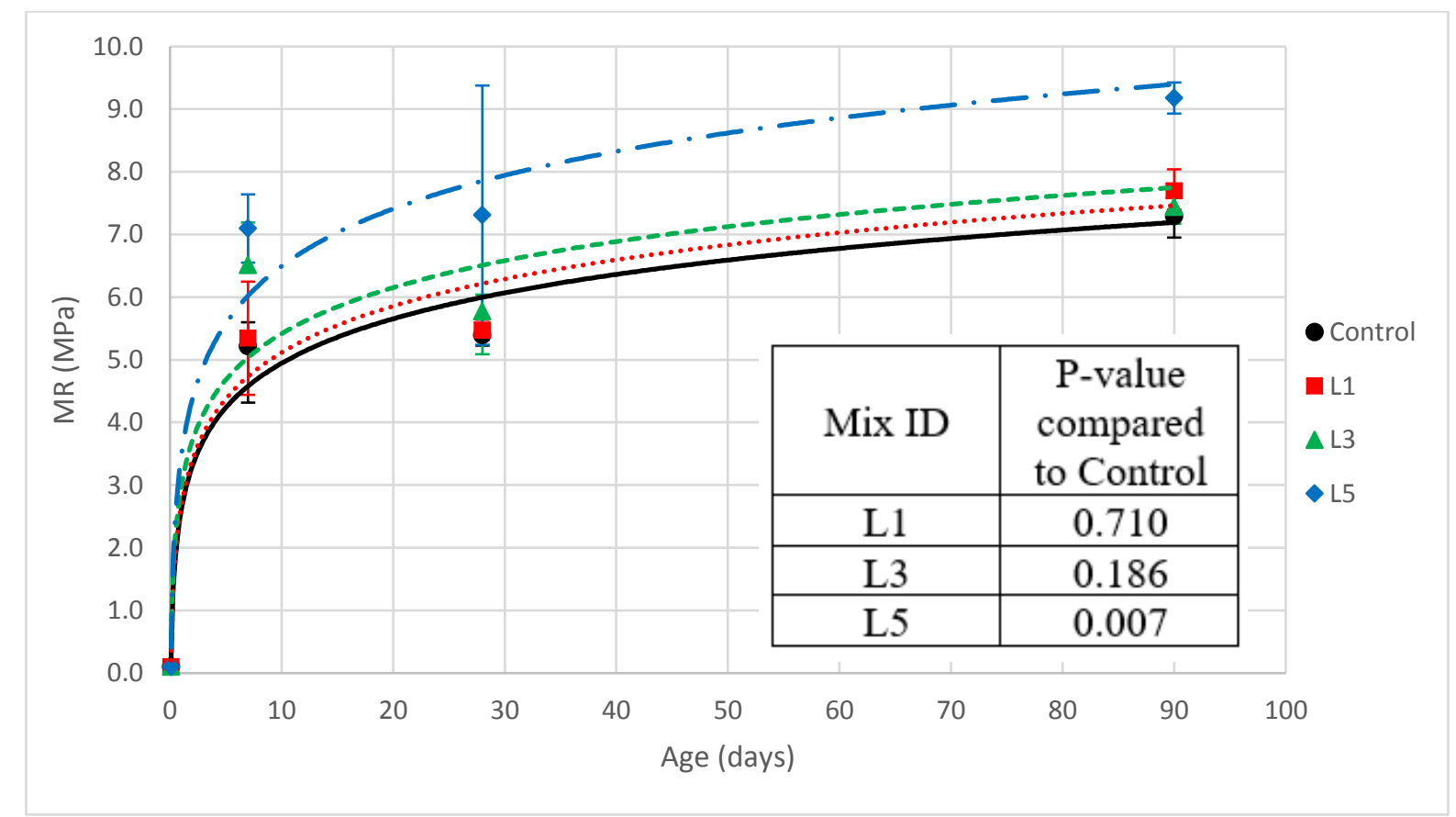

Figure 3.9 Flexural strength results at 7-, 28- and 90-day age during Phase II.

\subsubsection{Toughness Index}

Toughness index values were recorded at each of the test ages to compare post-peak loading of each GFRP mixture. Figure 3.10 shows the load-deflection curves for each test age. At each test age, the area under the load-deflection curve increases with an increase in 
GFRP content. This pattern of behavior shows that as the GFRP content increases, the toughness increases. The addition of GFRP in mortar shows the ability of the material to mitigate crack propagation and crack bridging during post-peak loading.

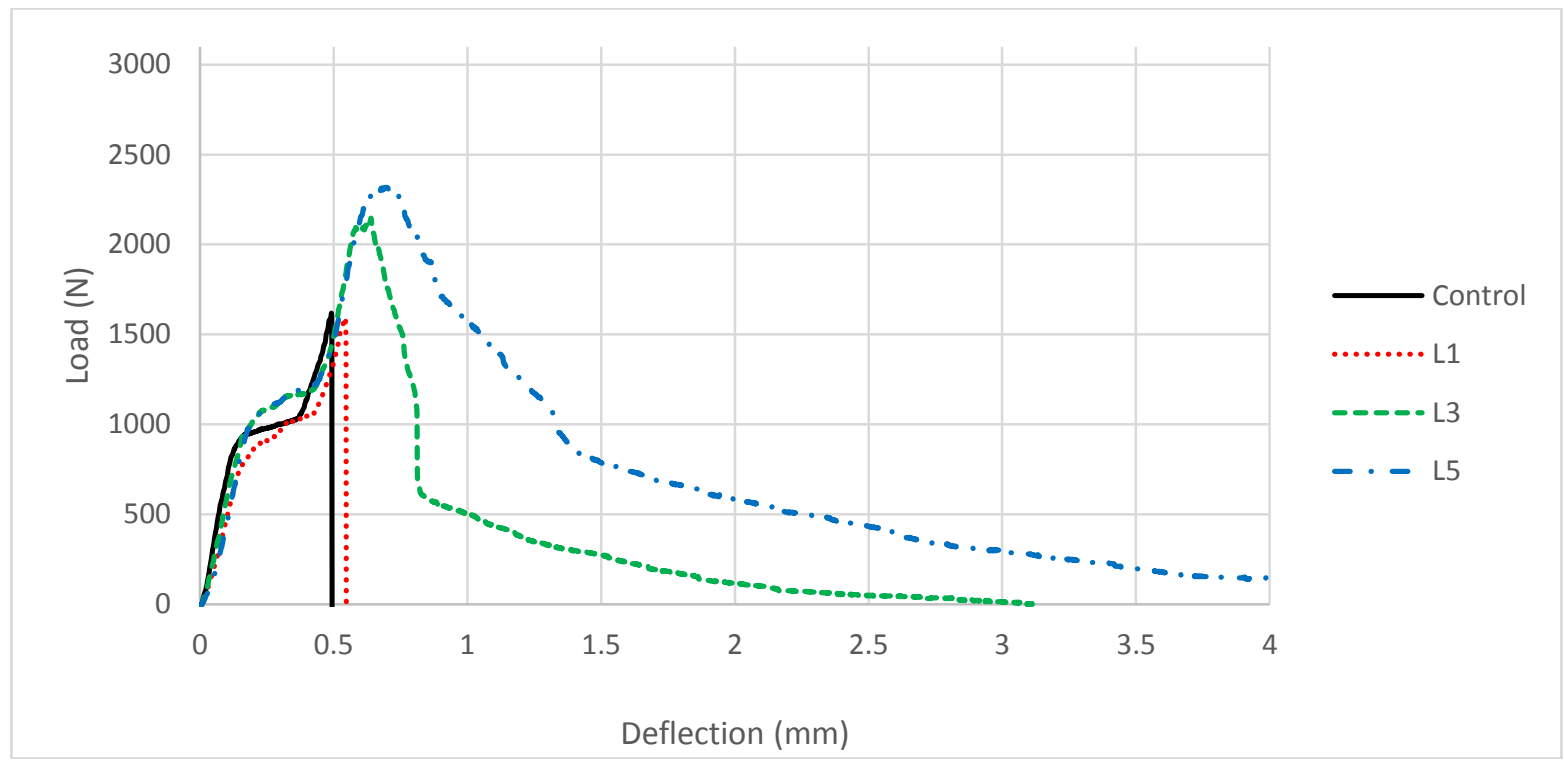

(a)

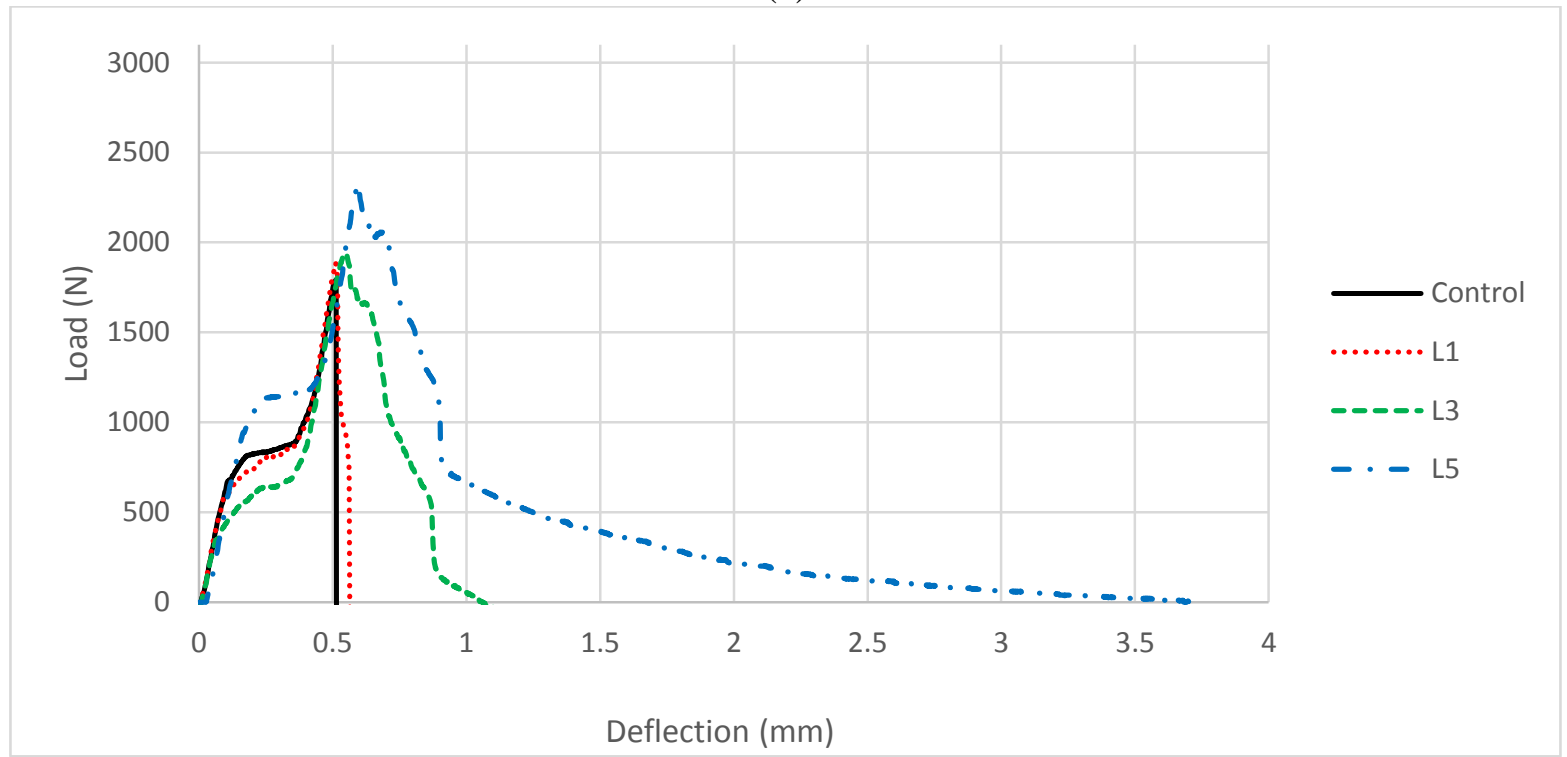

(b) 


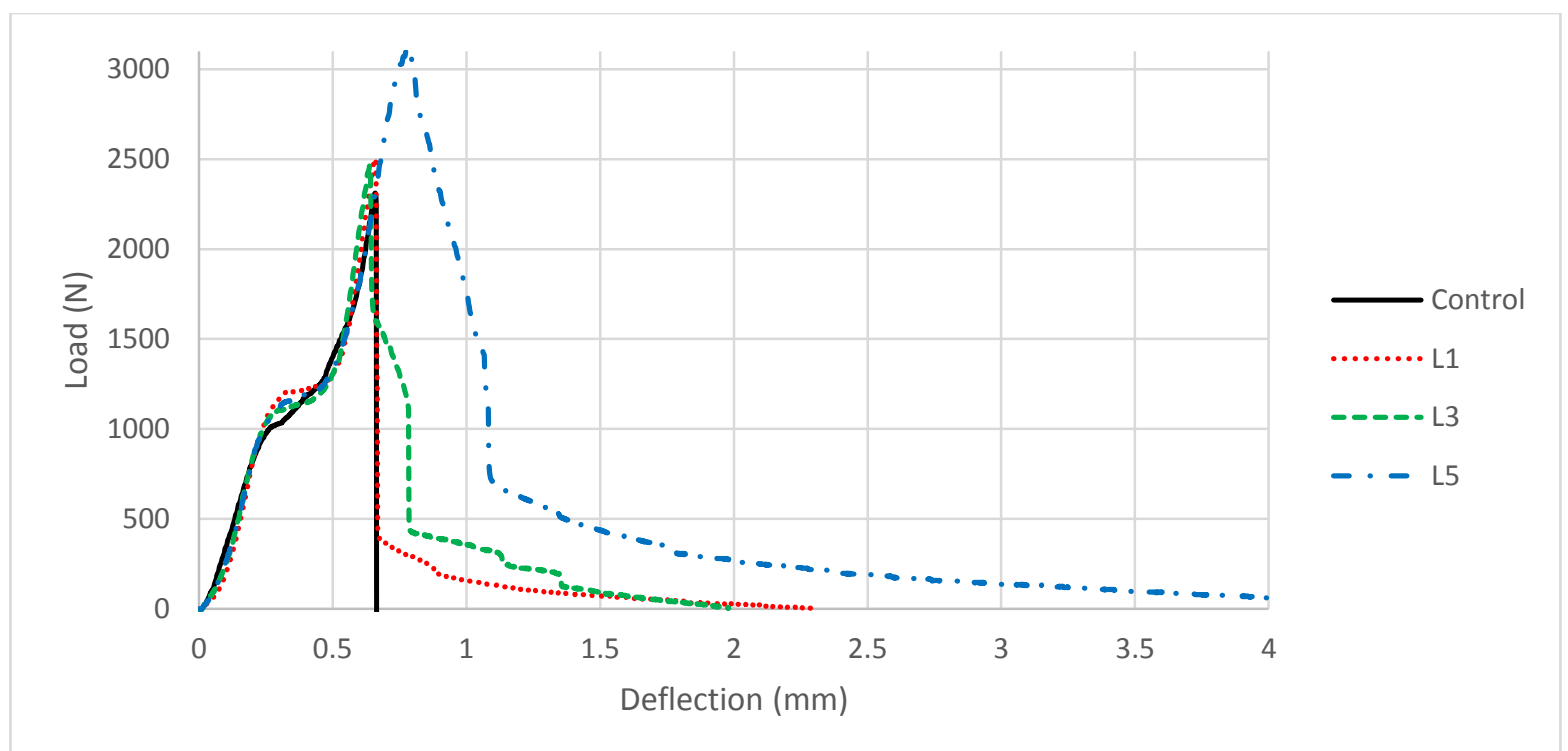

(c)

Figure 3.10 One load-deflection curve at 7-, 28- and 90-day age for each mixture used during Phase II.

Table 3.3 shows the TI values for each test age and mixture. The TI values were only reported if two or more test specimens resulted in a toughness value. $\mathrm{I}_{2}$ was recorded for all mixtures except the control at 90-day age, but the GFRP (L1, L3, and L5) index values were much higher than the index values of the control. L5 showed the most index values past $\mathrm{I}_{2}$, with the 90-day age reaching an I5 value of 1.08. L5 consistently showed more index values, while L1 and L3 resulted in more values at later test ages. All of the GFRP mixtures showed higher toughness than the control, which validates the visuals seen on the load-deflection curves in Figure 3.10. 
Table 3.3 Toughness index values at 7-, 28-, and 90-day age for each mixture during Phase II.

\begin{tabular}{|c|c|c|c|c|c|}
\hline \multirow{2}{*}{ Age } & \multirow{2}{*}{$\begin{array}{c}\text { Mixture } \\
\text { ID }\end{array}$} & \multicolumn{4}{|c|}{ Toughness Index Values } \\
\hline & & $I_{2}$ & $I_{3}$ & $I_{4}$ & $I_{5}$ \\
\hline \multirow{4}{*}{ 7-day } & Control & 1.01 & - & - & - \\
\hline & L1 & 1.13 & - & - & - \\
\hline & L3 & 1.81 & - & - & - \\
\hline & L5 & 2.16 & 1.28 & 1.13 & - \\
\hline \multirow{4}{*}{ 28-day } & Control & 1.01 & - & - & - \\
\hline & L1 & 1.07 & - & - & - \\
\hline & L3 & 1.74 & - & - & - \\
\hline & L5 & 1.87 & 1.28 & 1.13 & - \\
\hline \multirow{4}{*}{ 90-day } & Control & - & - & - & - \\
\hline & L1 & 1.17 & 1.05 & 1.04 & - \\
\hline & L3 & 1.61 & 1.11 & - & - \\
\hline & L5 & 1.87 & 1.23 & 1.13 & 1.08 \\
\hline
\end{tabular}

\subsubsection{ASR Expansion}

Length change was recorded periodically throughout the 35-day test period, and each value was compared with the zero reading, which was recorded after the specimen was soaked in the sodium hydroxide solution for 24 hours (Figure 3.11). The length change for L5 was only recorded until 21 days due to unavailability of the oven used for this experiment. The initial rise in all mixtures was due to thermal expansion, after which a stable length was recorded for all mixtures. All of the mixtures were below the $0.1 \%$ threshold specified by ASTM 1260 (2014), which may be due to the large polyester resin content in the material that wraps around the glass and prevents any ASR reaction from occurring. L1 and L5 resulted in more expansion than the control, but were still well below the threshold, while L3 resulted in less expansion than the control. 


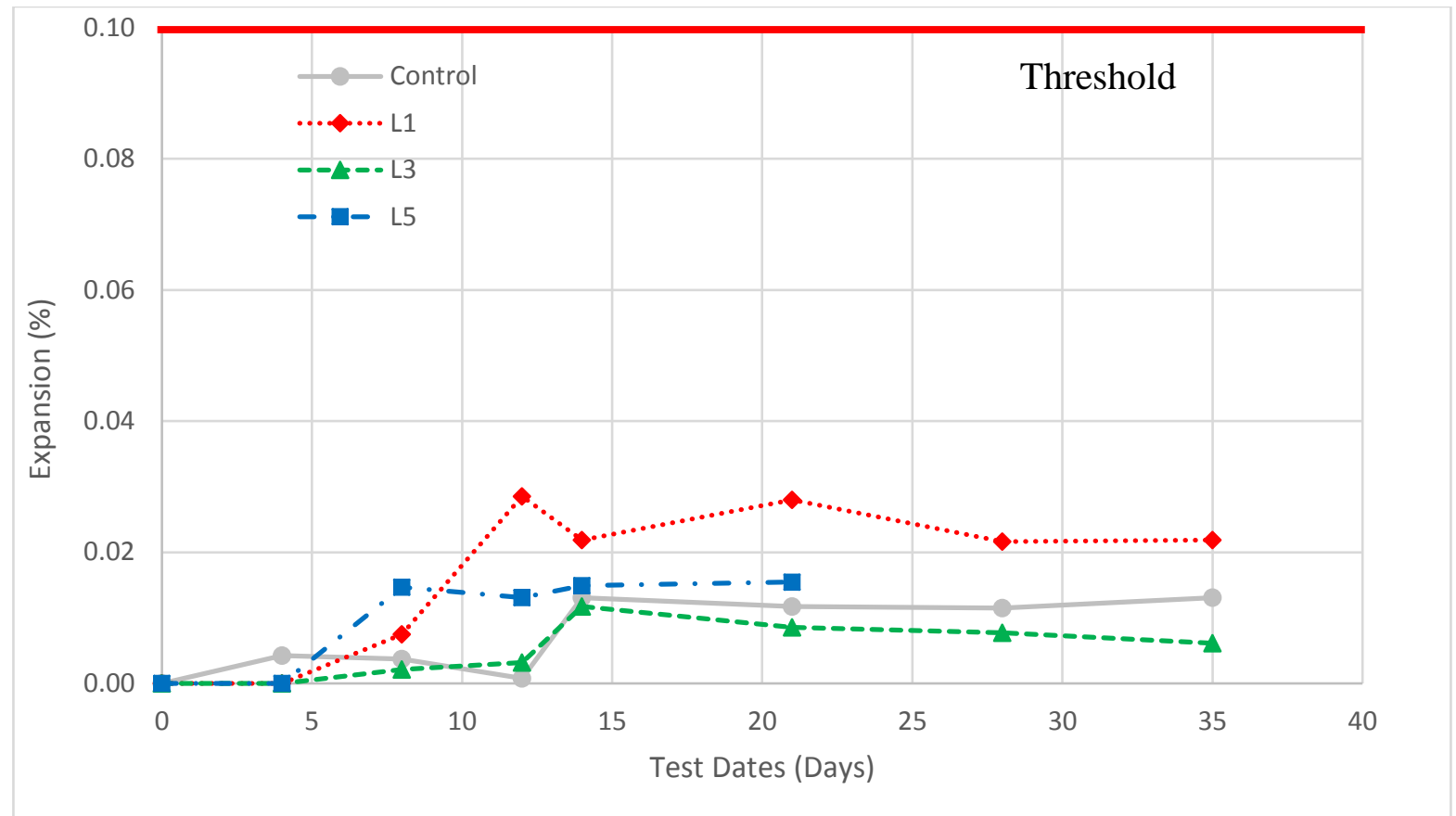

Figure 3.11 Length-change results to identify ASR expansion in each mixture during Phase II. 


\section{CHAPTER 4. CONCLUSIONS AND RECOMMENDATIONS}

This study was an investigation of the feasibility of reusing glass fiber reinforced polymer from end-of-life products in cement-based materials. Glass fiber reinforced polymer (GFRP) was implemented in mortar as a replacement for fine aggregate to test the material's influence on hardened density $(\rho)$, strength, toughness, and potentially hazardous expansion. Four different GFRP size groups and three different replacement percentages were tested. During Phase I, GFRP size groups (Large, Medium, Small, and Powder) were tested; the control contained no GFRP. Once the optimum size of Large was determined, the GFRP was implemented at zero, $1 \%, 3 \%$, and 5\% (Control, L1, L3, and L5) replacement of sand during Phase II. Based on the results gathered during Phase I and Phase II, the following conclusions have been drawn:

- Compressive strength $\left(f^{\prime} c\right)$ reductions occurred during Phase I for all GFRP sizes except Large, which saw a f'c increase of 2\%; however, the GFRP specimens remained more intact than the control specimens, which shattered during failure. During Phase II, L1 resulted in some increases in $f^{\prime} c$ at some ages. L1 and L3 also experienced slight decreases up to $9 \%$ reduction in compressive strength, while L5 decreased up to $66 \%$ at 28-day age. The decreases in $f^{\prime} c$ may be due to more difficult compaction at higher volume percentages.

- Flexural strength (MR) increased for Large and Small GFRP during Phase I, while Medium saw a $6 \%$ reduction. Powder resulted in a 30\% reduction of flexural strength.

During Phase II, all GFRP contents increased MR, with the highest increases being 5\%, $25 \%$, and $35 \%$ for L1, L3, and L5, respectively. Large was used for Phase II, which was a fiber-like material and helped bridge cracks to increase flexural strength. 
- During Phase I, Large resulted in the highest toughness index (TI) values compared with any of the other sizes. During Phase II, all GFRP contents resulted in higher toughness indices compared with the control. As the GFRP content increased, the area under the load-deflection curves increased, resulting in toughness indices at higher deflections. The GFRP helped mitigate crack propagation and bridged cracks, which led to more TI values for the specimens with GFRP incorporated.

- Length change was also monitored in accelerated testing due to concerns of glass causing alkali-silicate reaction (ASR) expansion in the mortar. This test was performed for all mixtures during Phase II of the study. L1 and L5 showed slightly more expansion than the control, while L3 was just below control. The initial rises in expansion for L1 and L5 may be due to thermal expansion. All mixtures, however, were well below the $0.1 \%$ threshold laid out in ASTM 1260 (2014).

The use of GFRP in mortar showed that fiber-like strand particles resulted in higher flexural strengths and toughness indices compared with a plain mortar mixture. When implementing the GFRP at different volume percentages, we observed that L1 and L3 resulted in comparable $f^{\prime} c$ results and increased MR, in comparison with the control mixture. L5 resulted in high MR, but had large decreases in compressive strength. The toughness of all GFRP mixtures was greater than that of the control, and all GFRP mixtures resulted in acceptable ASR expansion.

Future work will include implementing GFRP in various mixtures of mortar as well as in Portland cement concrete to ensure that GFRP performs on a larger scale and to identify working mixtures for other size groups. The next phase will provide more insight on the influences of 
GFRP in concrete and allow researchers to find ways to recycle and reuse large quantities of GFRP. 


\section{References}

Arulrajah, A., Disfani, M. M., Haghighi, H., Mohammadinia, A., and Horpibulsuk, S. (2015). "Modulus of rupture evaluation of cement stabilized recycled glass/recycled concrete aggregate blends." Construction and Building Materials, 84, 146-155.

Asokan, P., Osmani, M., and Price, A. D. F. (2009). “Assessing the recycling potential of glass fibre reinforced plastic waste in concrete and cement composites." Journal of Cleaner Production, 17, 821-829.

Asokan, P., Osmani, M., and Price, A. D. F. (2010). "Improvement of mechanical properties of glass fibre reinforced plastic waste powder filled concrete." Construction and Building Materials, 24, 448-460.

ASTM. C109. (2016). "Standard Test Method for Compressive Strength of Hydraulic Cement Mortars (Using 2-in. or [50-mm] Cube Specimens.” ASTM C109-2016, West Conshohocken, PA.

ASTM. C127. (2015). "Standard Test Method for Relative Density (Specific Gravity) and Absorption of Coarse Aggregate.” ASTM C127-2015, West Conshohocken, PA.

ASTM. C305. (2014). "Standard Practice for Mechanical Mixing of Hydraulic Cement Pastes and Mortars of Plastic Consistency.” ASTM C305-2014, West Conshohocken, PA.

ASTM. C348 (2014). "Standard Test Method for Flexural Strength of Hydraulic-Cement Mortars.” ASTM C348-2014, West Conshohocken, PA.

ASTM. C1018. (1997). "Standard Test Method for Flexural Toughness and First-Crack Strength of Fiber-Reinforced Concrete (Using Beam With Third-Point Loading).” ASTM C10181997, West Conshohocken, PA. 
ASTM. C1260. (2014). "Standard Test Method for Potential Alkali Reactivity of Aggregates (Mortar-Bar Method).” ASTM C1260-2014, West Conshohocken, PA.

Correia, J. R., Almeida, N. M., and Figueira, J. R. (2011). “Recycling for FRP composites: reusing fine GFRP waste in concrete mixtures." Journal of Cleaner Production, 19, $1745-1753$.

Fox, T. R. (2016). "Recycling Wind turbine blade composite material as aggregate in concrete." Graduate Theses and Dissertations, Iowa State University.

Hui, Z., and Sun, W. (2011). "Study of properties of mortar containing cathode ray tubes (CRT) glass as replacement of river sand fine aggregate." Construction and Building Materials, $25,4059-4064$.

Ismail, Z. Z., and Al-Hashmi, E. A. (2009). "Recycling of waste glass as partial replacement for fine aggregate in concrete." Waste Management, 29, 655-659.

Ling, T., and Poon, C. (2011). "Utilization of recycled glass derived from cathode ray tube glass as fine aggregate in cement mortar." Journal of Hazardous Materials, 192, 451-456.

Ling, T., and Poon, C. (2012). "A comparative study on the feasible use of recycled beverage and CRT funnel glass as fine aggregate in cement mortar." Journal of Cleaner Production, 29-30, 46-52.

Ling, T., Poon, C., Lam, W., Chan, T., and Fung, K. K. (2012). "Utilization of recycled cathode ray tube glass in cement mortar for X-ray radiation-shielding applications." Journal of Hazardous Materials, 199-200, 321-327.

Shayan, A., and Xu, A. (2006). "Performance of glass powder as a pozzolanic material in concrete: A field trial on concrete slabs." Cement and Concrete Research, 36, 457-468. 
Shi, C., and Zheng, K. (2007). "A review on the use of waste glasses in the production of cement and concrete." Resources, Conservation and Recycling, 52, 234-247.

Topcu, I. B., and Canbaz, Mehmet. (2004). "Properties of concrete containing waste glass." Cement and Concrete Research, 34, 267-274.

Yazdanbakhsh, A., Bank, L. C., Chen, C., and Tian, Y. (2017). "FRP-Needles as Discrete Reinforcement in Concrete." Journal of Materials in Civil Engineering, 29(10): 04017175.

Yazdanbakhsh, A., Bank, L. C., Rieder, K., Tian, Y., and Chen, C. (2018). "Concrete with discrete slender elements from mechanically recycled wind turbine blades." Resources, Conservation \& Recycling, 128, 11-21. 